\title{
Defect engineering for quantum grade rare-earth nanocrystals
}

Shuping Liu, ${ }^{\dagger, \ddagger}$ Alexandre Fossati, ${ }^{\dagger}$ Diana Serrano, ${ }^{*}, \dagger$ Alexandre Tallaire, ${ }^{\dagger}$ Alban Ferrier, ${ }^{\dagger}, \boldsymbol{a}$ and Philippe Goldner*,†

$\dagger$ Chimie ParisTech, PSL University, CNRS, Institut de Recherche de Chimie Paris, F-75005 Paris, France

$\ddagger$ Shenzhen Institute for Quantum Science and Engineering and Department of Physics, Southern University of Science and Technology, 1088 Xueyuan Avenue, 518055 Shenzhen, China

ФSorbonne Université, Faculté des Sciences et Ingénierie, UFR 933, F-75005 Paris, France

E-mail: diana.serrano@chimieparistech.psl.eu; philippe.goldner@chimieparistech.psl.eu 


\begin{abstract}
Nanostructured systems that combine optical and spin transitions offer new functionalities for quantum technologies by providing efficient quantum light-matter interfaces. Rare earth (RE) ions doped nanoparticles are promising in this field as they show long-lived optical and spin quantum states, a unique feature among nanomaterials. However, further development of their use in highly demanding applications such as scalable single ion based quantum processors, requires controlling defects that currently limit coherence lifetimes. In this work, we demonstrate that a novel posttreatment process that includes multi-step high-temperature annealing followed by high-power microwave oxygen plasma processing advantageously improves key properties for quantum technologies. We obtain single crystalline nanoparticles (NPs) of $100 \mathrm{~nm}$ diameter, presenting bulk-like inhomogeneous linewidths $\left(\Gamma_{\mathrm{inh}}\right)$ and population lifetimes $\left(T_{1}\right)$. Furthermore, a significant coherence lifetime $\left(T_{2}\right)$ extension, up to a factor of 5 , is successfully achieved by modifying the oxygen-related point defects in the NPs by the oxygen plasma treatment. These promising results confirm the potential of these engineered RE NPs to integrate devices such as cavity-based single photon sources, quantum memories and processors. In addition, our strategy could be applied to a large variety of oxides to obtain outstanding crystalline quality NPs for a broad range of applications.
\end{abstract}

\title{
Keywords
}

$\mathrm{Y}_{2} \mathrm{O}_{3}$, rare-earth nanoparticles, single crystal, defect engineering, quantum technologies. 
Quantum technologies (QT) aim at new functionalities in the fields of computing, sensing and communications that classical systems cannot reach ${ }^{1}$. This is because QT use, as a fundamental resource, superposition or entangled states that are only available in quantum systems. The lifetime of these quantum states, so-called coherence lifetime $T_{2}$, is a key parameter for designing materials for QT. In this respect, rare earth (RE) doped crystals have emerged as a promising platform for optical QT among other solid state systems such as color centers in diamond or quantum dots since they show a unique combination of long coherence lifetimes for optical and spin transitions ${ }^{2-4}$. In bulk single crystals like $\mathrm{Eu}^{3+}: \mathrm{Y}_{2} \mathrm{SiO}_{5}$ and at liquid helium temperatures, optical $T_{2}$ can reach the ms range ${ }^{5}$ whereas nuclear spin $T_{2}$ can reach $10 \mathrm{~s}$ of $\mathrm{ms}^{6}$. Hours long $T_{2}$ have even been observed when control techniques to decrease perturbations from the ions' environment are applied ${ }^{7}$. These outstanding properties have led to many demonstrations in the field of quantum memories for light including long time storage of single photons ${ }^{8}$, photonic entanglement storage ${ }^{9}$, and light to matter teleportation ${ }^{10}$. At the nanoscale, new possibilities appear based on coupling to optical and microwave micro- or nano-cavities for greatly enhanced interactions with light or accessing extreme sensitivities together with nanometer spatial resolution ${ }^{11-15}$. These developments can however be hindered by the stronger perturbations to the quantum states often found in nano-structures due to e.g. larger surface to volume ratio, impurities introduced by bottomup synthesis, or defects related to lower crystalline quality. Nevertheless, we were able to show that europium doped $\mathrm{Y}_{2} \mathrm{O}_{3}$ nanoparticles can have optical coherence lifetimes as long as $10 \mu \mathrm{s}$ at $1.3 \mathrm{~K}^{16,17}$, while nuclear spin $T_{2}$ can reach up to $8 \mathrm{~ms}$ at $5 \mathrm{~K}^{18}$. Similar values have been observed in $\operatorname{Pr}^{3+}: \mathrm{Y}_{2} \mathrm{O}_{3}$ nanoparticles ${ }^{19}$. Since these particles can be moreover coupled to high finesse optical fiber cavities $^{13}$, these long coherence lifetimes open a broad range of applications from single ion quantum memories to scalable quantum processors through single photon sources. While RE nanoparticles show the longest $T_{2}$ values among nanomaterials carrying optically addressable spins, they are still shorter by one to two orders of magnitude compared to single crystals or transparent ceramics ${ }^{6,20-22}$. 
In this paper, we demonstrate that post-treatment using an oxygen plasma driven by a $\mathrm{kW}$ range microwave (MW) power source is able to extend the optical $T_{2}$ up to a factor of 5. These results have been obtained in $100 \mathrm{~nm}$ diameter nanoparticles with negligible aggregation and single crystalline structure enabled by a multistep high-temperature annealing. A comprehensive study by coherent and high-resolution optical spectroscopy, time-resolved photoluminescence (PL), cathodo luminescence (CL) and electron paramagnetic resonance (EPR), allowed us to reveal oxygen related defects and monitor their evolution in the course of the treatments. We propose that our plasma treatment is able to decrease oxygen vacancy defects between which electrons can tunnel. Importantly, this effect occurs in the volume of the particle and is not limited to surface, in sharp contrast with conventional soft plasma cleaning procedures ${ }^{23}$. Through the decrease of this particular type of defect, electric fluctuations are reduced and coherence lifetimes increased. These results open the way to RE doped particles with much improved optical and structural properties for nanoscale optical quantum technologies. In addition, this plasma treatment, never used on RE doped nanoparticles to our knowledge, could be of interest in fields where defect control is important such as nano-sensors, bio-imaging, or micro-electronics.

\section{Results and discussion}

A novel strategy combining chemical synthesis, high-temperature annealing and high-power microwave oxygen plasma processing is here presented to obtain single crystalline $\mathrm{Eu}^{3+}: \mathrm{Y}_{2} \mathrm{O}_{3}$ NPs $(0.3 \%$ at. $)$ with improved optical $T_{2}$ for nanoscale optical quantum technologies. The full procedure is displayed in Figure 1: Amorphous $\mathrm{Y}(\mathrm{OH}) \mathrm{CO}_{3} \cdot n \mathrm{H}_{2} \mathrm{O}: \mathrm{Eu}^{3+}$ precursor NPs (YOC: $\mathrm{Eu}^{3+}$ ) are synthesized by homogeneous precipitation (see Methods) ${ }^{24}$. Welldispersed polycrystalline $\mathrm{Eu}^{3+}: \mathrm{Y}_{2} \mathrm{O}_{3}$ NPs (0.3\%at.) are obtained after annealing for $18 \mathrm{~h}$ at $800{ }^{\circ} \mathrm{C}$. A second annealing follows at $1200{ }^{\circ} \mathrm{C}$ for $6 \mathrm{~h}$. This step yields single crystalline NPs presenting bulk-like luminescence properties. The last step consists in treating the NPs 
under oxygen plasma for two times 3 minutes with a MW excitation power of $900 \mathrm{~W}$. Under these conditions, the sample reaches a temperature of approximately $500{ }^{\circ} \mathrm{C}$, evidenced by glowing, and a consistent improvement of the NPs optical coherence properties is observed. For clarity, once annealed, twice annealed and further oxygen plasma treated NPs will be hereinafter identified as $\mathrm{NP}_{800}, \mathrm{NP}_{1200}$ and $\mathrm{NP}_{\mathrm{MWP}}$ respectively.

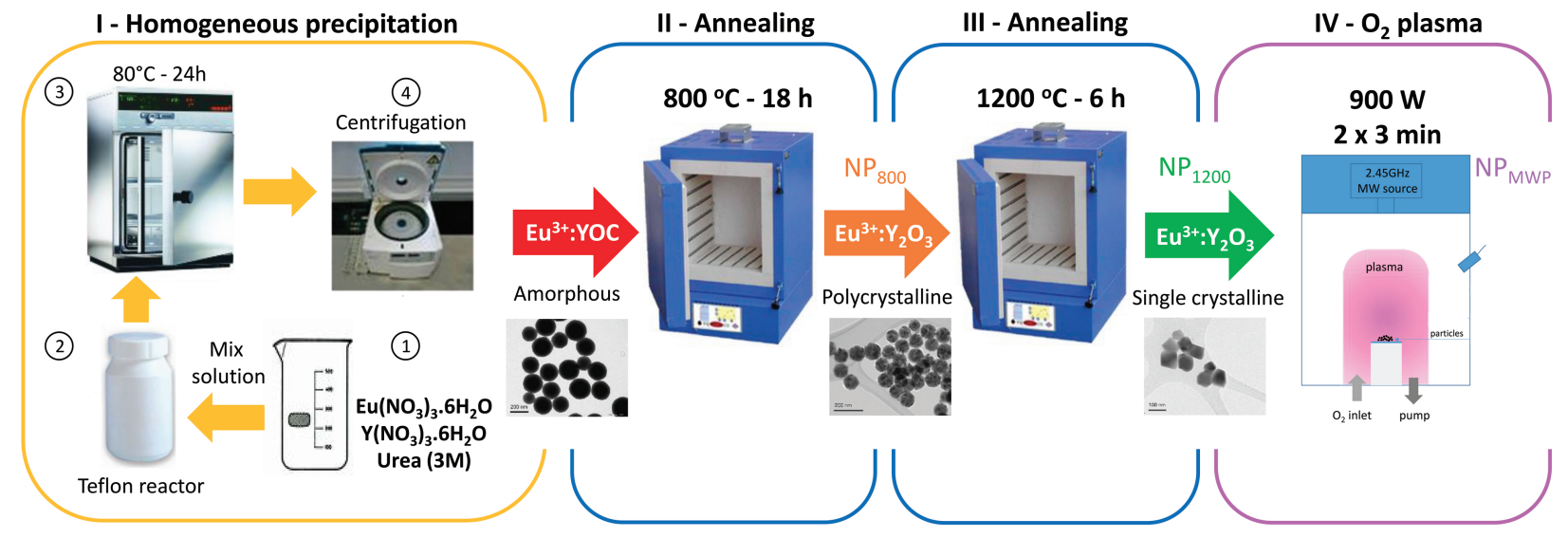

Figure 1: Schematic representation of the synthesis and post-treatment strategy. The homogeneous precipitation synthesis is here described in four steps: (1) Preparation of the rare-earth nitrates and urea aqueous solutions. (2) Addition of the mixed solution to a teflon reactor. (3) Calcination for $24 \mathrm{~h}$ at $85{ }^{\circ} \mathrm{C}$. (4) Washing and collection of $\mathrm{Eu}^{3+}: \mathrm{YOC}$ NPs. The amorphous $\mathrm{Eu}^{3+}$ :YOC NPs are then first annealed for $18 \mathrm{~h}$ at $800{ }^{\circ} \mathrm{C}$ followed by a second annealing at $1200{ }^{\circ} \mathrm{C}$ for $6 \mathrm{~h}$. Both annealing steps are done in air atmosphere. The twice-annealed NPs are finally treated under pure oxygen plasma for two times 3 minutes at $900 \mathrm{~W}$ MW excitation power, reaching a temperature of $\sim 500{ }^{\circ} \mathrm{C}$. Refer to the Methods for more details.

\section{Structural characterizations}

Structural and morphological evolutions induced by the different post-synthesis treatments are shown in Figure 2. The $\mathrm{NP}_{800}$ sample presents polycrystalline features and the particle size follows a log-normal distribution with an average value of $102 \pm 17 \mathrm{~nm}$ and crystalline domains of $30 \pm 10 \mathrm{~nm}$ (Figure 2 (b-b2-b3)). In contrast, the NPs structure and morphology clearly changes after the second annealing at $1200{ }^{\circ} \mathrm{C}$. Indeed, $\mathrm{NP}_{1200}$ present single crystalline features with crystallographic planes that extend over the whole particle, and a 
morphology characterized by plain facets and sharp edges (Figure 2(c)). In addition, we observe that performing two high-temperature annealing steps helps limiting particle aggregation with respect to a single annealing treatment at $1200{ }^{\circ} \mathrm{C}$ for $18 \mathrm{~h}^{17}$. No further morphological modifications are observed after the oxygen plasma processing (Figure 2 (dd2)) and the latter does not lead to further particle aggregation either. The average particle size of the final $\mathrm{NP}_{\mathrm{MWP}}$ is estimated at $100 \pm 31 \mathrm{~nm}$ (Figure $\mathbf{2}(\mathbf{d} 3)$ ).
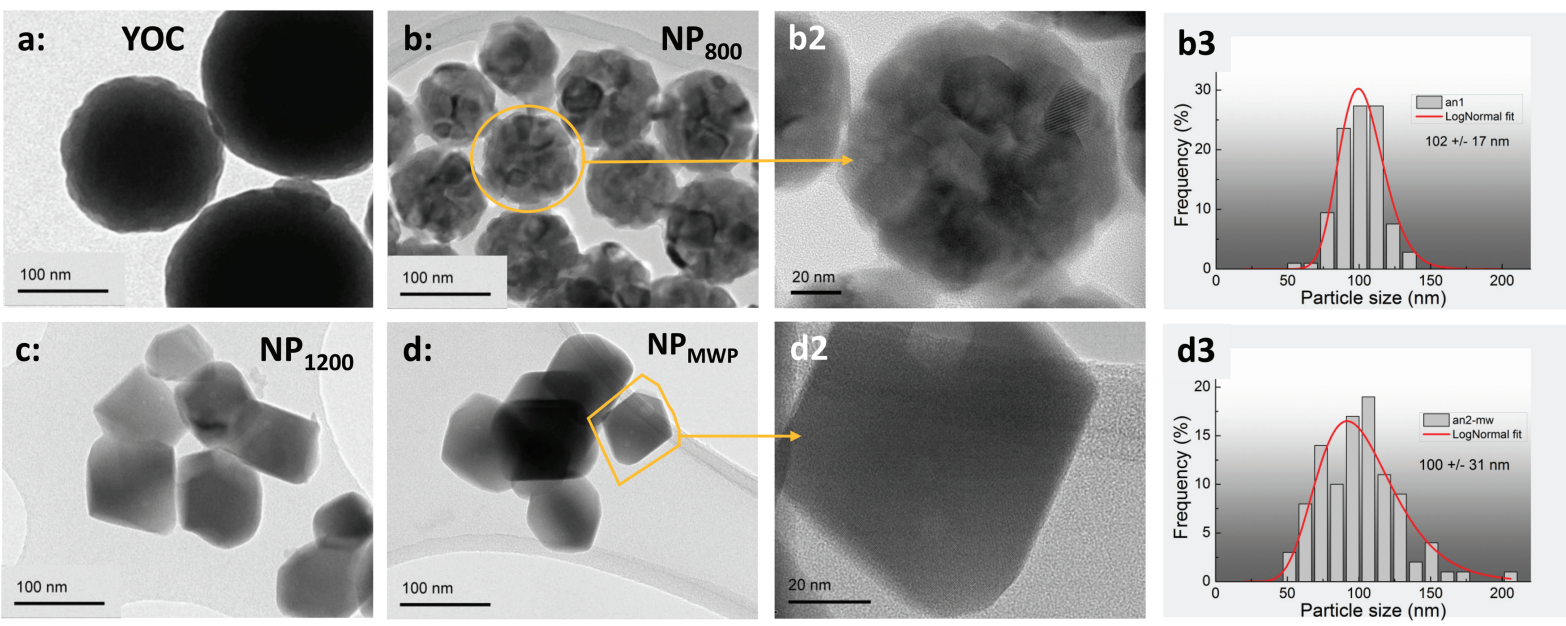

Figure 2: Structural and morphological evolution of the NPs along the different posttreatments shown by TEM. (a) As synthesized $\mathrm{Eu}^{3+}$ :YOC NPs. (b) NP 800 . (b2) Zoom on one isolated $\mathrm{NP}_{800}$. (b3) Size distribution for $\mathrm{NP}_{800}$. (c) $\mathrm{NP}_{1200}$. (d) $\mathrm{NP}_{\mathrm{MWP}}$. (d2) Zoom on one isolated $\mathrm{NP}_{\mathrm{MWP}}$. (d3) Size distribution for $\mathrm{NP}_{\mathrm{MWP}}$.

The NPs transition from polycrystalline to single crystalline is also evidenced by X-ray diffraction (XRD). As displayed in Figure 3, the characteristic diffraction pattern of the $\mathrm{Y}_{2} \mathrm{O}_{3}$ cubic phase (Ia-3 space group, JCPDS 01-080-6433) is found in all cases. However, the peak broadening is remarkably reduced after the second annealing at $1200{ }^{\circ} \mathrm{C}$. This is due to the increase of the crystalline domain size, in full agreement with TEM results. The crystalline domain size, obtained from the diffraction peaks' full-width half maximum (FWHM) using Scherrer's equation (see Methods), is found equal to $30 \pm 2 \mathrm{~nm}$ in $\mathrm{NP}_{800}$, increasing up to $111 \pm 13 \mathrm{~nm}$ in $\mathrm{NP}_{1200}$. The average crystalline domain size in $\mathrm{NP}_{\mathrm{MwP}}$ is calculated at $121 \pm 15 \mathrm{~nm}$. These values are comparable to particle sizes observed by TEM 
(Figure 2). In conclusion, TEM imaging and XRD diffraction results demonstrate that the synthesis and post-treatment strategy proposed here enables obtaining dispersed single crystalline $\mathrm{Y}_{2} \mathrm{O}_{3}: \mathrm{Eu}^{3+}$ NPs of $\sim 100 \mathrm{~nm}$ average size.

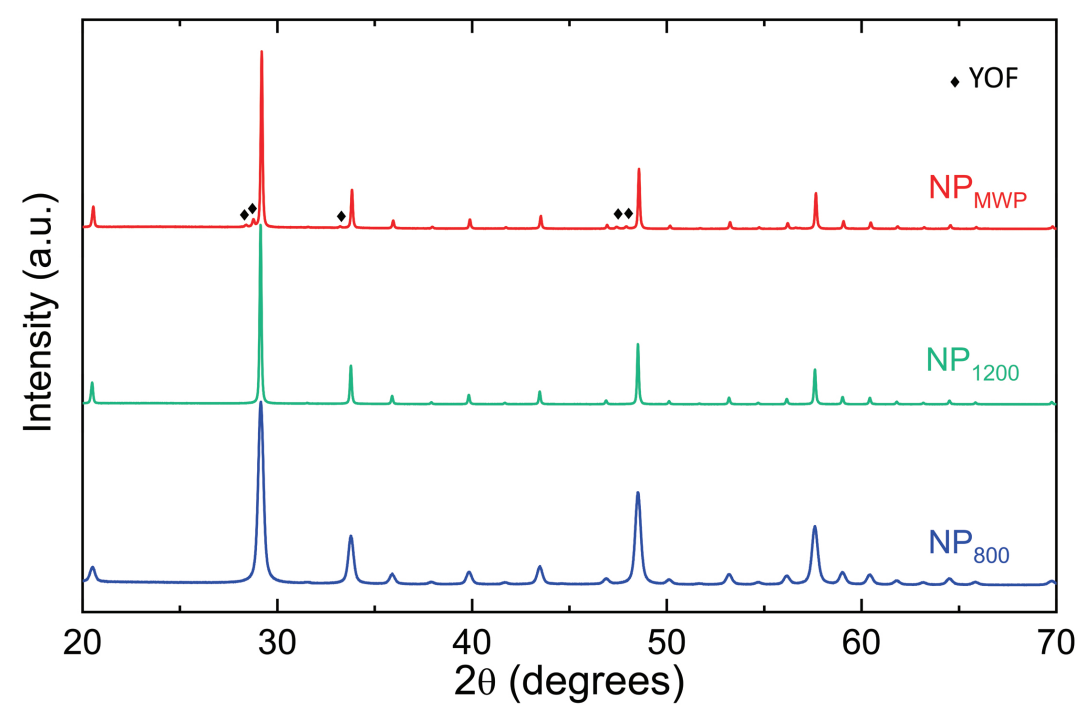

Figure 3: XRD patterns from $\mathrm{NP}_{800}, \mathrm{NP}_{1200}$ and $\mathrm{NP}_{\mathrm{MWP}}$. Rhomb symbols indicate the position of diffraction peaks assigned to a parasitic yttrium oxyfluoride (YOF) rhomboedral phase (JCPDF: 71-2100) due to a pollution from the plasma experimental equipment. The amount of this phase is estimated at $3-5 \%$. Curves are vertically shifted for clarity.

\section{High-resolution and coherent optical spectroscopy of $\mathrm{Eu}^{3+}$ in $\mathrm{Y}_{2} \mathrm{O}_{3} \mathrm{NPs}$}

High-resolution optical spectroscopy techniques are highly sensitive, providing insight into modifications in the RE ions environment. They are particularly useful when those changes are minor, therefore unnoticeable by most characterization techniques. For instance, important information can be extracted from the study of the RE's optical inhomogeneous lines $\left(\Gamma_{\text {inh }}\right)$. At low temperatures, the RE transitions are inhomogeneously broadened due strain induced by defects, with broadenings ranging from hundreds of $\mathrm{MHz}$ to hundreds of $\mathrm{GHz}^{25}$. These defects include the RE dopants themselves, but also other uncontrolled impurities. Therefore, the analysis of transition linewidths and lineshapes provides insight into the amount and nature of defects in the material ${ }^{26,27}$. Another spectroscopic parameter providing very valuable information about the ions environment and of key importance for 
QT applications is the optical coherence lifetime $T_{2}$. Indeed, $T_{2}$ is extremely sensitive to dynamic perturbations such as electric or magnetic field fluctuations or dynamical disorder modes (TLS) ${ }^{16}$. In the following, we study the ${ }^{7} \mathrm{~F}_{0} \leftrightarrow{ }^{5} \mathrm{D}_{0}$ transition of $\mathrm{Eu}^{3+}$ at $580.883 \mathrm{~nm}$ (vac.), corresponding to $\mathrm{Eu}^{3+}$ ions at the $\mathrm{C}_{2}$ symmetry site ${ }^{24}$, and we compare inhomogeneous linewidths and $T_{2}$ results from $\mathrm{NP}_{1200}$ and $\mathrm{NP}_{\mathrm{MWP}}$ samples.
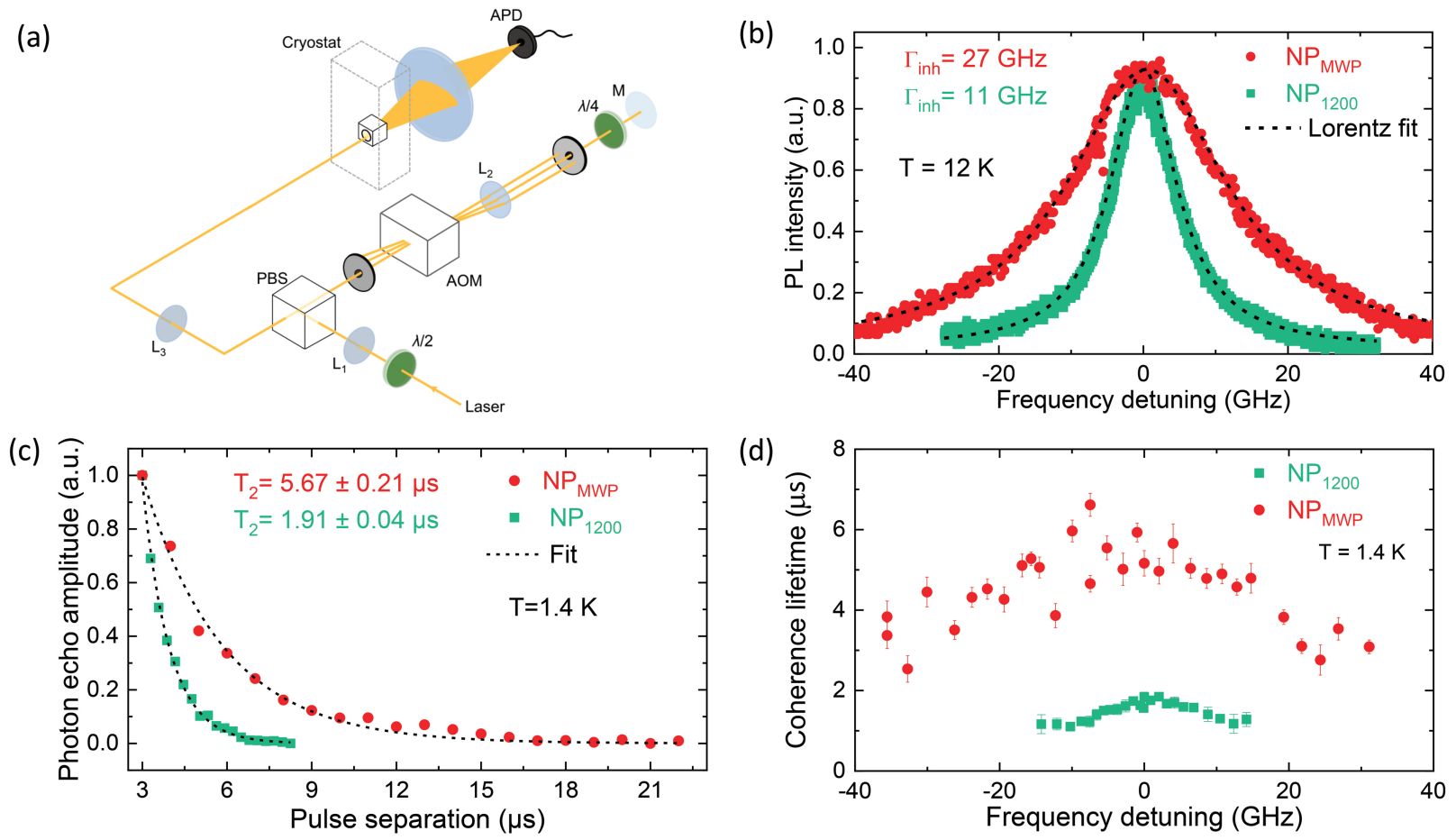

Figure 4: (a) Experimental setup. AOM stands for acousto-optic modulator, PBS for polarising beam splitter, APD for avalanche photodiode and L and M represent lenses and mirrors. (b) $\Gamma_{\text {inh }}$ for the ${ }^{7} \mathrm{~F}_{0} \rightarrow{ }^{5} \mathrm{D}_{0} \mathrm{Eu}^{3+}$ transition in $\mathrm{NP}_{1200}$ and $\mathrm{NP}_{\text {MWP }}$ samples. $\Gamma_{\text {inh }}$ values are estimated by Lorentzian fit. The optical transition frequency at 0 detuning corresponds to $516.0979 \pm 0.0002 \mathrm{THz}\left(580.8830 \pm 0.0001 \mathrm{~nm}\right.$ in vac.) for $\mathrm{NP}_{1200}$, and $516.0992 \pm 0.0002$ $\mathrm{THz}\left(580.8815 \pm 0.0001 \mathrm{~nm}\right.$ in vac.) for $\mathrm{NP}_{\mathrm{MWP}}$. (c) Photon echo decays from $\mathrm{NP}_{1200}$ and $\mathrm{NP}_{\text {MwP }}$ samples. $T_{2}$ values are derived by single exponential fit to the photon echo decay data (see Methods). (d) $T_{2}$ as a function of excitation frequency for $\mathrm{NP}_{1200}$ (green) and $\mathrm{NP}_{\text {MWP }}$ (red).

A schematic representation of the experimental setup used in these measurements is shown in Figure 4(a). For a more detailed description refer to the Methods section. Inhomogeneous linewidths measured at $12 \mathrm{~K}$ are displayed in Figure 4(b). Both lines present Lorentzian lineshape, indicating that the broadening originates from point defects ${ }^{26}$. In par- 
ticular, a FWHM of $11 \mathrm{GHz}$ is obtained from the $\mathrm{NP}_{1200}$ sample, equivalent to $0.0124 \mathrm{~nm}$ (or $0.37 \mathrm{~cm}^{-1}$ ). This is similar to values reported in $\mathrm{Eu}^{3+}: \mathrm{Y}_{2} \mathrm{O}_{3}$ transparent ceramics ${ }^{21}$ and larger $\mathrm{NPs}^{17,24}$. With an $\mathrm{Eu}^{3+}$ concentration of $0.3 \%$ at., the contribution to $\Gamma_{\mathrm{inh}}$ from $\mathrm{Eu}^{3+}$ ions is estimated at $6 \mathrm{GHz}$ by comparison to high-quality single crystals ${ }^{28}$. Therefore, an additional broadening of $5 \mathrm{GHz}$ is observed, revealing the presence of additional defects or impurities. This contribution is clearly larger in the $\mathrm{NP}_{\mathrm{MwP}}$ case, with $\Gamma_{\text {inh }}$ reaching 27 GHz. Thus, new point defects are created due to the MW-excited oxygen plasma action. In addition, the inhomogeneous line center is blueshifted of $\sim 1 \mathrm{GHz}$ in the $\mathrm{NP}_{\mathrm{MwP}}$ sample, pointing that the oxygen plasma processing induces compressive strain in the lattice ${ }^{27}$.

Interestingly, the optical coherence lifetime of $\mathrm{Eu}^{3+}$, measured at $1.4 \mathrm{~K}$ using the twopulse photon echo technique ${ }^{16}$ (see Methods for more details), is significantly improved by the MW oxygen plasma treatment. As displayed in Figure 4(c), a $T_{2}$ of $5.7 \pm 0.2 \mu \mathrm{s}$ is measured in the $\mathrm{NP}_{\mathrm{MWP}}$ sample. This is about 3 times longer than in the $\mathrm{NP}_{1200}$ sample $\left(\mathrm{T}_{2}=1.91 \pm 0.04 \mu \mathrm{s}\right)$. Furthermore, this improvement is not limited to ions absorbing at the central wavelength. Instead, it is observed along the whole inhomogeneous absorption line with an enhancement factor varying between 3 and 5 (Figure 4(d)). This result indicates that the oxygen plasma treatment acts on all ions, and it is not limited to e.g. $\mathrm{Eu}^{3+}$ ions close to surface. For the latter, transition frequencies are indeed expected to be shifted from the line center. We note that the maximum $T_{2}$ obtained here is longer than that observed in $5 \mu \mathrm{m}$ size particles containing $60 \mathrm{~nm}$ nanocrystals synthesized by solvothermal method $\left(\mathrm{T}_{2}=3.7 \mu \mathrm{s}\right)^{29}$, and it is comparable to values reported in $400 \mathrm{~nm}$ size $\mathrm{NPs}\left(\mathrm{T}_{2}=7 \mu \mathrm{s}\right)^{16}$ and some bulk single crystals ${ }^{28}$. In addition, the enhancement effect is not limited to these particular NPs as optical $T_{2}$ enhancement by oxygen plasma has also been recently observed in chemically etched $\mathrm{Eu}^{3+}: \mathrm{Y}_{2} \mathrm{O}_{3} \mathrm{NPs}^{17}$ as well as $\mathrm{Pr}^{3+}: \mathrm{Y}_{2} \mathrm{O}_{3} \mathrm{NPs}$ of different sizes ${ }^{19}$.

We investigated the effect on $T_{2}$ of varying different plasma parameters, such as nature and pressure of the forming gases and treatment duration time. (Figure 5). By this, we conclude that coherence lifetimes are only improved when the plasma forming gases contain 


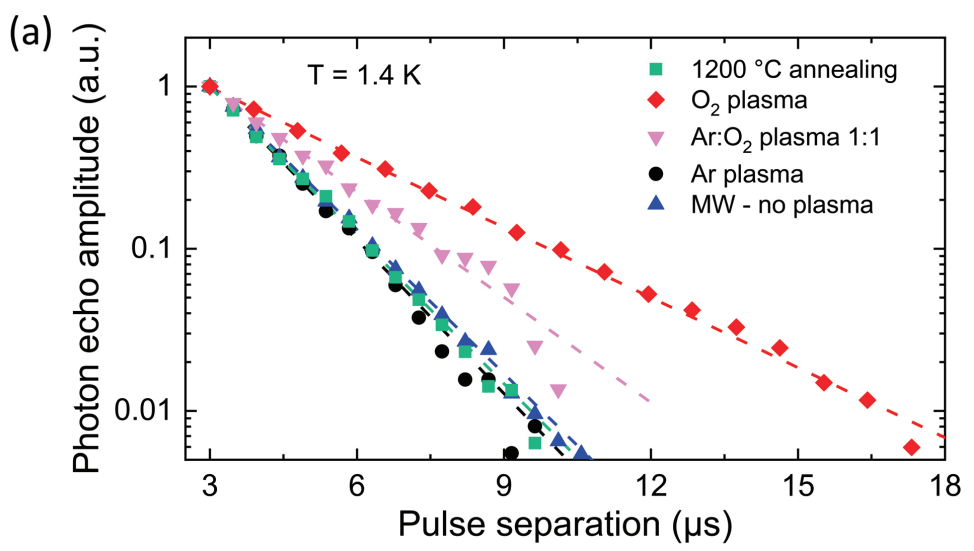

(b)

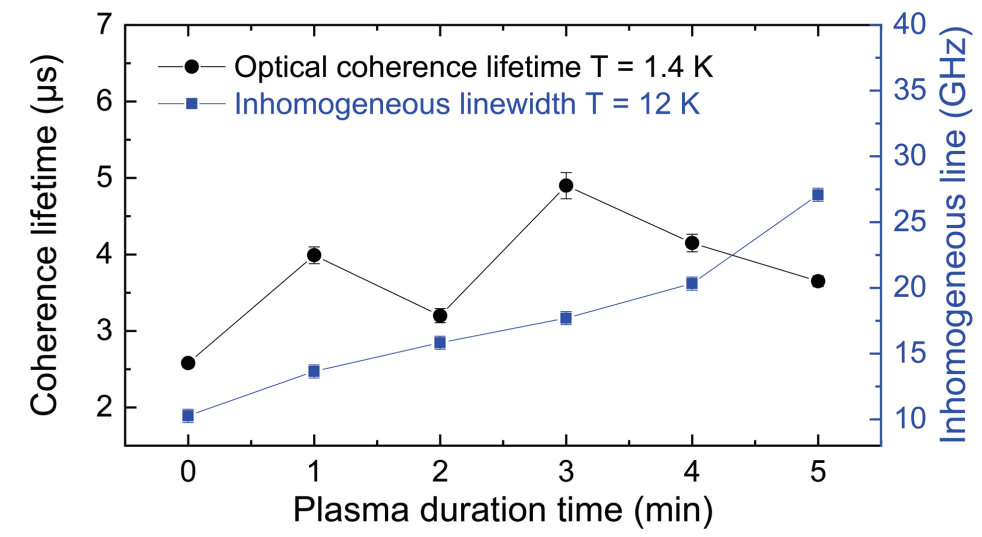

Figure 5: (a) Photon echo decays of $\mathrm{Eu}^{3+}: \mathrm{Y}_{2} \mathrm{O}_{3}$ NPs treated two times for 3 minutes under different plasma conditions. A batch of 400-nm-diameter NPs was used in this study (see Methods for more details) (b) $T_{2}$ and $\Gamma_{\text {inh }}$ evolution as a function of plasma duration time. The longest $T_{2}$ is obtained for a plama duration of 3 minutes. Further optimization revealed the optimum sequence of two times 3 minutes applied elsewhere. A batch of 140-nm-diameter NPs was used in this study (see Methods for more details). 
oxygen, and that the enhancement effect increases when increasing the oxygen content. In contrast, a pure argon gas flow exhibited no impact (Figure 5(a)). A control experiment in which the particles were treated under high-power MW radiation at atmospheric pressure (i.e. no plasma) was also carried out, showing no effect. The impact of the plasma duration time on $T_{2}$ and $\Gamma_{\text {inh }}$ is given in Figure 5(b). When tuning the oxygen plasma duration time from 1 to 5 minutes, $T_{2}$ is observed to first increase and then decrease, yielding the longest $T_{2}$ or larger improvement factor, for a treatment duration of 3 minutes. At the same time, a monotone inhomogeneous linewidth increase is obtained when increasing the treatment duration time. In summary, we find a clear correlation between the presence of oxygen in the plasma forming gases and the increase of optical $T_{2}$ in the NPs. The enhancement effect, of a factor 3-5, is consistently observed in all ions (Figure $\mathbf{4}(\mathbf{d})$ ), and also for different batches of NPs (Figure 5) ${ }^{17,19}$. In parallel, the MW oxygen plasma treatment induces a broadening of the optical inhomogeneous line, indicating and increased number of point defects.

\section{FT-IR, luminescence and EPR characterizations}

A series of optical and magnetic characterizations were performed on $\mathrm{NP}_{1200}$ and $\mathrm{NP}_{\mathrm{MWP}}$ samples, before and after MW oxygen plasma treatment, to gain understanding about the mechanisms behind the observed $T_{2}$ enhancement and $\Gamma_{\text {inh }}$ broadening. Those include Fourier transform infrared spectroscopy (FT-IR), time-resolved photoluminescence (PL), cathodoluminescence (CL) and electron paramagnetic resonance (EPR).

Figure 6 shows the evolution of FT-IR spectra from the $\mathrm{Eu}^{3+}$ : YOC precursor through the subsequent treatments. The $\mathrm{Eu}^{3+}:$ YOC spectrum is characterized by strong absorption signals in the $1400-1500 \mathrm{~cm}^{-1}$ and $3000-3400 \mathrm{~cm}^{-1}$ regions, corresponding to $\mathrm{C}-\mathrm{O}$ and O-H bond vibrations ${ }^{30}$. The $\mathrm{Y}_{2} \mathrm{O}_{3}$ phase formed after annealing at $800{ }^{\circ} \mathrm{C}$ is confirmed by the appearance of $\mathrm{Y}-\mathrm{O}$ bonds ${ }^{31}$ at $565 \mathrm{~cm}^{-1}$. However, C-O and $\mathrm{O}-\mathrm{H}$ vibration bands are still observed and persist in the $\mathrm{NP}_{1200}$ and $\mathrm{NP}_{\mathrm{MWP}}$ samples. Since at $1200{ }^{\circ} \mathrm{C}$ any residual 
carbonates are expected to be removed and these bands show no clear evolution from $\mathrm{NP}_{1200}$ to $\mathrm{NP}_{\mathrm{MWP}}$, we conclude that they are due to surface-adsorbed molecules from ambient atmosphere $^{32}$. Therefore, they seem to play no role in the observed $T_{2}$ increase and $\Gamma_{\text {inh }}$ broadening after oxygen plasma processing.

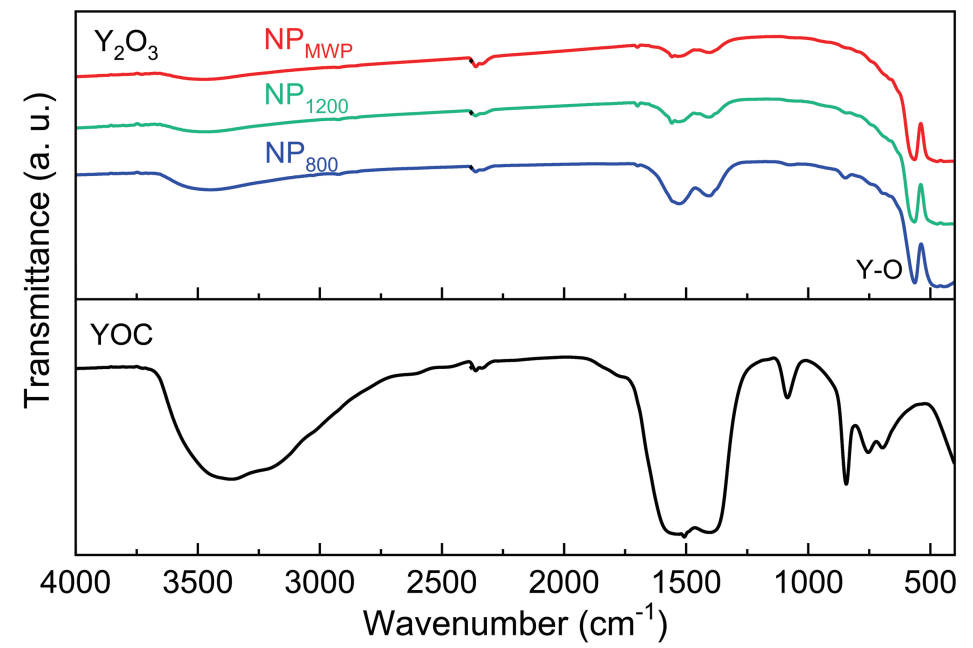

Figure 6: FT-IR spectra of $\mathrm{Eu}^{3+}$ :YOC precursor NPs, $\mathrm{NP}_{800}, \mathrm{NP}_{1200}$ and $\mathrm{NP}_{\mathrm{MwP}}$. Curves are vertically shifted for clarity.

In addition, no fluorescence lifetime variations were observed between $\mathrm{NP}_{1200}$ and $\mathrm{NP}_{\mathrm{MWP}}$ samples. This was evidenced by measuring the fluorescence lifetimes $\left(T_{1}\right)$ of the ${ }^{5} \mathrm{D}_{0},{ }^{5} \mathrm{D}_{1}$ and ${ }^{5} \mathrm{D}_{2}$ excited state levels (Figure $7(\mathbf{a})$ ). Those were recorded from the $\mathrm{Eu}^{3+}$ emissions at $611 \mathrm{~nm}\left({ }^{5} \mathrm{D}_{0} \rightarrow{ }^{7} \mathrm{~F}_{2}\right), 535 \mathrm{~nm}\left({ }^{5} \mathrm{D}_{1} \rightarrow{ }^{7} \mathrm{~F}_{1}\right)$, and $516 \mathrm{~nm}\left({ }^{5} \mathrm{D}_{2} \rightarrow{ }^{7} \mathrm{~F}_{2}\right)$, under pulsed excitation at $465 \mathrm{~nm}\left({ }^{7} \mathrm{~F}_{0} \rightarrow{ }^{5} \mathrm{D}_{2}\right)$, yielding $\mathrm{T}_{1}$ values of $1.35 \mathrm{~ms}, 95 \mu$ s and $42 \mu$ s respectively (Figure 7(b)). In contrast, cathodoluminescence spectra display clear differences with the applied treatments (Figure $7(\mathbf{c})$ ). All samples show the characteristic $\mathrm{Eu}^{3+}$ emissions in the 400-700 nm range, corresponding to the ${ }^{5} \mathrm{D}_{J}(J=0,1,2,3) \rightarrow{ }^{7} \mathrm{~F}_{J}(J=0,1,2,3,4)$ transitions. Additionally, a broadband emission in the 250-400 nm range is observed. After being normalized to the $\mathrm{Eu}^{3+}{ }^{5} \mathrm{D}_{0} \rightarrow{ }^{7} \mathrm{~F}_{2}$ transition at $611 \mathrm{~nm}$, the intensity of this broad emission is observed to increase in the $\mathrm{NP}_{1200}$ sample and then, to slightly decrease after $\mathrm{MW}$ oxygen plasma processing. A similar CL emission band was reported in undoped $\mathrm{Y}_{2} \mathrm{O}_{3},{ }^{33}$ 
and has been observed in annealed $\mathrm{Eu}^{3+}: \mathrm{Y}_{2} \mathrm{O}_{3}$ thin films ${ }^{34}$. Based on these previous works, we attribute this broad emission to native defects in $\mathrm{Y}_{2} \mathrm{O}_{3}{ }^{35,36}$. In particular, this band has been assigned to oxygen interstitials $\left(\mathrm{O}_{\mathrm{i}}\right)^{33}$, resulting from oxygen diffusion into the NPs. In contrast, no evidence of $\mathrm{Eu}^{2+}$ emission has been observed ${ }^{33}$.

(a)

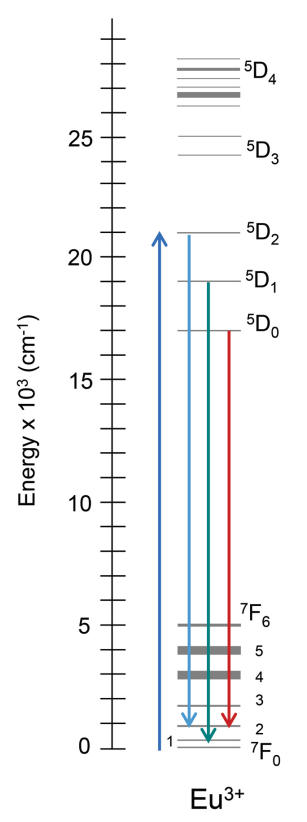

(b)

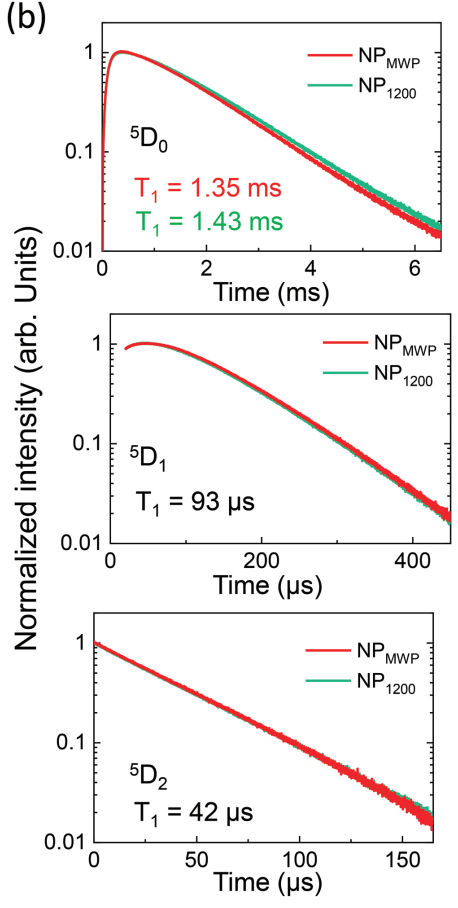

(c)

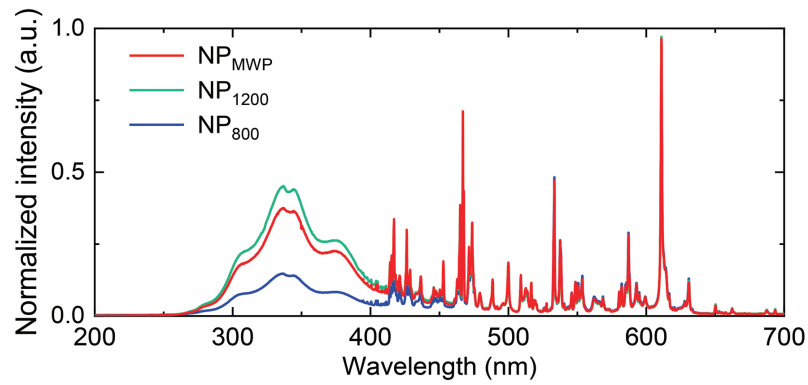

(d)

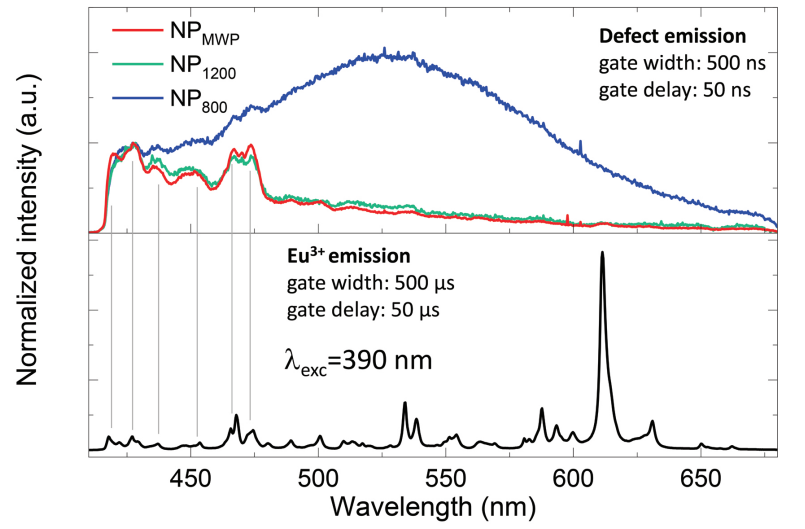

Figure 7: (a) $\mathrm{Eu}^{3+}$ energy level diagram indicating the investigated transitions. (b) PL decays from $\mathrm{NP}_{1200}$ and $\mathrm{NP}_{\mathrm{MWP}}$ samples. The population lifetime $T_{1}$ is measured by monitoring the $611 \mathrm{~nm}\left({ }^{5} \mathrm{D}_{0} \rightarrow{ }^{7} \mathrm{~F}_{2}\right), 535 \mathrm{~nm}\left({ }^{5} \mathrm{D}_{1} \rightarrow{ }^{7} \mathrm{~F}_{1}\right)$, and $516 \mathrm{~nm}\left({ }^{5} \mathrm{D}_{2} \rightarrow{ }^{7} \mathrm{~F}_{2}\right)$ emissions under pulsed excitation at $465 \mathrm{~nm}\left({ }^{7} \mathrm{~F}_{0} \rightarrow{ }^{5} \mathrm{D}_{2}\right)$. (c) CL spectra normalized to the $611 \mathrm{~nm} \mathrm{Eu}{ }^{3+}$ emission peak. (d) Time-resolved PL spectra under $390 \mathrm{~nm}$ excitation for two different time gates. Fast emissions from defects are evidenced by the short-time detection window from 50 ns to $550 \mathrm{~ns}$ (upper panel), while the regular $4 f-4 f \mathrm{Eu}^{3+}$ transitions dominate the emission spectrum for detection between $50 \mu$ s and $550 \mu$ s (lower panel).

To gain further insight into defect types and their concentration in the NPs, time-resolved PL and EPR studies were also performed. As illustrated in Figure 7(d), different PL spectra are obtained from the NPs depending on the applied treatments when using a gated detection. This technique enables separating short-lived emissions like those coming from defects (Figure $7(\mathrm{~d})$, upper panel), from longer-lived ones, in this case, the $\mathrm{Eu}^{3+} 4 f-4 f$ emissions (Figure $7(\mathbf{d})$, lower panel). In particular, a short-lived broadband emission is 
observed in the 400-650 $\mathrm{nm}$ range for the $\mathrm{NP}_{800}$ sample. A similar short-lived broadband has been previously observed in $\mathrm{Eu}^{3+}: \mathrm{Y}_{2} \mathrm{O}_{3}$ transparent ceramics ${ }^{21}$ and $\mathrm{Y}_{2} \mathrm{O}_{3}$ thin films ${ }^{37}$, and attributed to neutral oxygen vacancies $\left(\mathrm{V}_{\mathrm{O}}\right)^{21,38}$. After the second annealing at 1200 ${ }^{\circ} \mathrm{C}\left(\mathrm{NP}_{1200}\right)$, this broad emission band weakens, becoming indistinguishable from the background. Indeed, only $4 f-4 f$ emissions from $\mathrm{Eu}^{3+}$ ions can be indentified between 400 and 500 $\mathrm{nm}$ in $\mathrm{NP}_{1200}$ and $\mathrm{NP}_{\mathrm{MWP}}$ samples under the same recording conditions. Therefore, no difference could be detected before and after MW oxygen plasma processing by this technique. In contrast, electron paramagnetic resonance (EPR) provides interesting results.

EPR investigations were carried out at $4.5 \mathrm{~K}, 20 \mathrm{~K}, 70 \mathrm{~K}$ and $100 \mathrm{~K}$ respectively. Figure 8 shows normalized spectra from $\mathrm{NP}_{1200}$ and $\mathrm{NP}_{\mathrm{MWP}}$ samples. Two resonance lines at 335.1 $\mathrm{mT}$ (line I) and $341.3 \mathrm{mT}$ (line II) can be observed in both cases, corresponding to $\mathrm{g}=$ 2.004 and $\mathrm{g}=1.967$ respectively. Similar EPR signals have been previously observed in $\mathrm{Y}_{2} \mathrm{O}_{3}{ }^{21,39-41}$. Accordingly, the lines in Figure 8 were attributed to interstitial superoxide anions $\mathrm{O}_{2}^{-}$(line I), and charged oxygen vacancies $\mathrm{V}_{\mathrm{O}}^{+}$(line II) i.e. an oxygen vacancy center with a trapped electron. These two lines show different temperature dependences. In particular, the $\mathrm{O}_{2}^{-}$EPR signal saturates at low temperatures while the intensity of the $\mathrm{V}_{\mathrm{O}}^{+}$peak increases. Furthermore, it is observed that the $\mathrm{O}_{2}^{-}$signals are of similar intensities before and after MW oxygen plasma processing while the $\mathrm{V}_{\mathrm{O}}^{+}$signal is clearly stronger afterwards, indicating an increase of this type of defect. The EPR spectrum of $\mathrm{Eu}^{3+}: \mathrm{Y}_{2} \mathrm{O}_{3} \mathrm{NPs}$ after $800{ }^{\circ} \mathrm{C}$ annealing was also measured (Figure 10), revealing the presence of $\mathrm{O}_{2}^{-}$and $\mathrm{V}_{\mathrm{O}}^{+}$ centers. However, both appeared as very weak signals at this stage. It is worth noting that the evolution of the $\mathrm{O}_{2}^{-}$centers in EPR is very similar to that of the CL broadband emission (Figure $7(\mathbf{c}))$, attributed to interstitial oxygen centers $\left(\mathrm{O}_{\mathrm{i}}\right)$. We note too that no EPR signals from $\mathrm{Eu}^{2+}$ ions were detected, in agreement with CL results (Figure $7(\mathbf{c})$ ).

In conclusion, from CL, PL and EPR characterizations, we demonstrate the ability of the high-temperature annealing and MW oxygen plasma post-synthesis treatments to modify the oxygen-related native defects in the NPs. Those are already modified between the first 


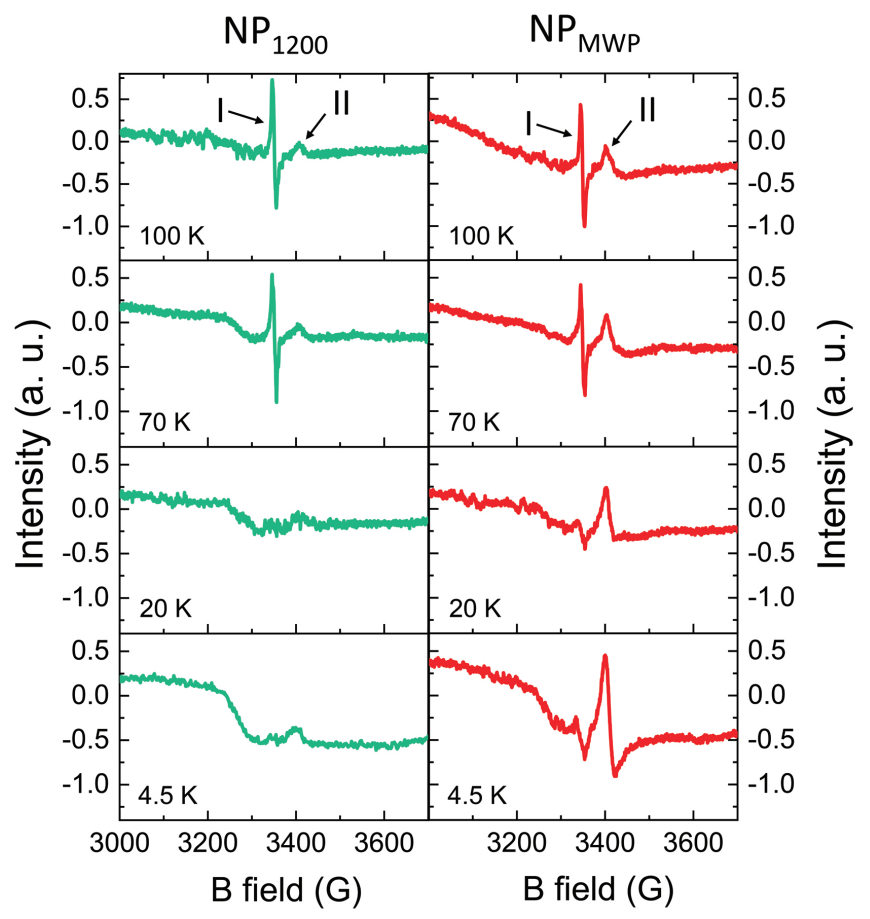

Figure 8: EPR spectra $\mathrm{NP}_{1200}$ and $\mathrm{NP}_{\mathrm{MWP}}$ samples recorded at different temperatures. Two signals are identified, referred to as I and II, corresponding to interstitial superoxide anions $\left(\mathrm{O}_{2}^{-}\right)$and charged oxygen vacancies $\left(\mathrm{V}_{\mathrm{O}}^{+}\right)$respectively.

annealing at $800{ }^{\circ} \mathrm{C}$ and the second annealing at $1200{ }^{\circ} \mathrm{C}$, with the observed increase of interstitial $\mathrm{O}_{2}^{-}$(Figure $\left.7(\mathbf{c})\right)$ and the reduction of the number of neutral oxygen vacancies $\left(V_{\mathrm{O}}\right)$ (Figure $\left.7(\mathrm{~d})\right)$. Interestingly, a more specific effect was revealed by EPR: the increase in the number of charged oxygen vacancies $\left(\mathrm{V}_{\mathrm{O}}^{+}\right)$following the $\mathrm{MW}$ oxygen plasma processing.

\section{Discussion}

Oxygen vacancies and oxygen interstitials are point defects abundantly found in oxide matrices, and in particular, in $\mathrm{Y}_{2} \mathrm{O}_{3}{ }^{35,36}$. Among the vacancies, we often distinguish between neutral $\left(\mathrm{V}_{\mathrm{O}}\right)$ and charged $\left(\mathrm{V}_{\mathrm{O}}^{+}\right)$oxygen vacancies, also referred to as $\mathrm{F}$ and $\mathrm{F}^{+}$centers in literature respectively ${ }^{38}$. Neutral vacancies have two trapped electrons, therefore same charge as the missing oxygen anion, while charged vacancies have a single trapped electron. Doublycharged vacancies or $\mathrm{V}_{\mathrm{O}}^{++}$i.e. without any trapped electron, can also be found (Figure 9). Several species of oxygen interstitials $\left(\mathrm{O}_{i}\right)$ can also be found, ${ }^{35,36}$ depending on their charge, 
and if they are present in radical form $(\mathrm{O})$ or in molecular form $\left(\mathrm{O}_{2}\right)$. The presence and relative amounts of all these defects can strongly vary depending on the synthesis conditions, and on the different post-treatments applied to the material, impacting its structural, electrical and transport properties ${ }^{35,42,43}$. As an example, the presence of oxygen vacancies modifies the dielectric properties of oxyde materials ${ }^{35,44}$ and contribute to electric conduction ${ }^{45}$. According to the present study, they could also be playing a major role in the optical dephasing mechanisms in $\mathrm{Eu}^{3+}: \mathrm{Y}_{2} \mathrm{O}_{3}$ NPs, leading to $T_{2}$ shortening i.e. homogeneous linewidth $\left(\Gamma_{\mathrm{h}}\right)$ broadening, with the two related by $\Gamma_{\mathrm{h}}=\left(\pi T_{2}\right)^{-1}$. For Eu ${ }^{3+}$ ions in $\mathrm{Y}_{2} \mathrm{O}_{3} \mathrm{NPs}_{\mathrm{s}} \Gamma_{\mathrm{h}}$ depends on several contributions defined as ${ }^{16}$ :

$$
\Gamma_{\mathrm{h}}=\Gamma_{\text {pop }}+\Gamma_{\text {Temp }}+\Gamma_{\text {magnetic }}+\Gamma_{\text {electric }}
$$

$\Gamma_{\text {pop }}$ represents line broadening related to the excited-state population lifetime, calculated as $\Gamma_{\text {pop }}=\left(2 \pi T_{1}\right)^{-1}$. $\Gamma_{\text {Temp }}$ refers to temperature-dependent dephasing mechanisms. In the particular case of $\mathrm{Eu}^{3+}: \mathrm{Y}_{2} \mathrm{O}_{3} \mathrm{NPs}$, at $1.4 \mathrm{~K}$, those are mostly due to two-level systems (TLS) related to residual disorder, resulting in a linear temperature dependence ${ }^{16}$. $\Gamma_{\text {magnetic }}$ stands for ion-spin and spin-spin magnetic interactions. Finally, by $\Gamma_{\text {electric }}$ we refer to line broadening induced by fluctuating electric fields. This term is usually neglected in bulk single crystal while it is a major contribution in NPs. Indeed, the three first contributions in Eq. 1 are largely insufficient to explain the measured optical homogeneous linewidth of $45 \mathrm{kHz}$ in 400-nm-diameter $\mathrm{Eu}^{3+}: \mathrm{Y}_{2} \mathrm{O}_{3} \mathrm{NPs}^{16}$. A plausible source of electric noise in nanomaterials is the surface. Indeed, surface states are very often blamed for both electric and magnetic perturbations resulting in $T_{2}$ decrease in nanomaterials ${ }^{46}$. Besides the surface, the native point defects constitute another possible source of electric noise. In particular, phenomena like charge tunneling between charged oxygen vacancies can induce electric field fluctuations in the $\mathrm{Eu}^{3+}$ ions environment, reducing $T_{2}$. 
In the present work we have shown that both high-temperature annealing and MW oxygen plasma treatments result in oxygen diffusion into the NPs leading to oxygen vacancy recombination and oxygen excess. However, the mechanisms involved are not strictly equivalent for these two treatments. In the annealing case, $\mathrm{O}$ diffusion must be preceded by $\mathrm{O}_{2}$ adsorption to the NPs surface and then dissociation. This mechanism is enhanced by the annealing temperature as demonstrated by the reduction of the oxygen vacancies from $\mathrm{NP}_{800}$ to $\mathrm{NP}_{1200}($ Figure $7(\mathbf{d}))$. We note that $T_{2}$ must be very short in the $\mathrm{NP}_{800}$ sample as photon echoes cannot be detected while microsecond-long $T_{2}$ is obtained in $\mathrm{NP}_{1200}$ (Table 1). This can be related to the observed oxygen vacancies reduction, but also to other mechanisms. In particular, the crystalline domain size is largely increased from $30 \mathrm{~nm}$ to $~ 110 \mathrm{~nm}$ by the second annealing. The impact of the crystalline domain size on $T_{2}$ has been suggested in previous investigations, indicating that $T_{2}$ increases when the surface to volume ratio at the crystalline domain level decreases ${ }^{17-19}$. In contrast, a direct correlation between oxygen diffusion, defects modification and enhanced $T_{2}$ is observed in the oxygen plasma case. For this post-treatment, the diffusion process is more efficient as radical oxygen atoms are already present in the plasma (Figure 11). Therefore, those can directly diffuse inside the material after adsorption at the surface. Moreover, the high temperature reached by the NPs during the treatment $\left(500{ }^{\circ} \mathrm{C}\right)$ is probably enhancing this diffusion. As a result, the optical $T_{2}$ is increased of a factor 3-5 by few minutes of oxygen plasma treatment while no improvement is observed when further increasing the annealing time before plasma processing.

Table 1: Summary of results from $\mathrm{NP}_{1200}$ and $\mathrm{NP}_{\mathrm{MWP}}$ samples.

\begin{tabular}{lcc}
\hline Parameter & $\mathrm{NP}_{1200}$ & $\mathrm{NP}_{\text {MWP }}$ \\
\hline Particle size $(\mathrm{nm})$ & $100 \pm 31$ & $100 \pm 31$ \\
Crystalline domain size $(\mathrm{nm})$ & $111 \pm 13$ & $121 \pm 15$ \\
$\Gamma_{\mathrm{inh}}(\mathrm{GHz})$ & $11 \pm 1$ & $27 \pm 1$ \\
$\mathrm{~T}_{1}(\mathrm{~ms})$ & 1.43 & 1.35 \\
$\mathrm{~T}_{2}(\mu \mathrm{s})$ & $1.91 \pm 0.04$ & $5.67 \pm 0.21$ \\
$\Gamma_{\mathrm{h}}(\mathrm{kHz})$ & $167 \pm 7$ & $56 \pm 4$ \\
\hline
\end{tabular}


The increase in charged oxygen vacancies $\left(\mathrm{V}_{\mathrm{O}}^{+}\right)$, revealed by EPR, is a very interesting specific effect associated to the MW oxygen plasma processing. It provides a deeper insight into the complex dephasing mechanisms taking place in the NPs and how the oxygen diffusion induced by this treatment counteracts them. Based on the present results, we propose that electric noise originates from charge tunneling between neighboring $V_{O}$ and $\mathrm{V}_{\mathrm{O}}^{+}$centers. Oxygen deficiency conditions can lead to such pairs in the crystalline matrix, their removal being responsible for the observed $T_{2}$ improvement after oxygen plasma. Two possible reactions between a diffusing $\mathrm{O}$ atom and a $\left(\mathrm{V}_{\mathrm{O}}-\mathrm{V}_{\mathrm{O}}^{+}\right)$pair can be foreseen:

- $\left(\mathrm{V}_{\mathrm{O}}+\mathrm{V}_{\mathrm{O}}^{+}\right)+\mathrm{O} \rightarrow \mathrm{O}_{\mathrm{O}}+\mathrm{V}_{\mathrm{O}}^{+}$

- $\left(\mathrm{V}_{\mathrm{O}}+\mathrm{V}_{\mathrm{O}}^{+}\right)+\mathrm{O} \rightarrow 2 \mathrm{~V}_{\mathrm{O}}^{+}+\mathrm{O}_{\mathrm{i}}^{-}$

where $\mathrm{O}_{\mathrm{O}}$ represents a recombined oxygen anion at a regular lattice site and $\mathrm{O}_{\mathrm{i}}^{-}$a negatively-charged interstitial oxygen atom. The result of these reactions is consistent with the observed experimental results as they yield to $\mathrm{O}_{\mathrm{i}}^{-}$increase, overall reduction of the number of oxygen vacancies, and relative increase of the $\mathrm{V}_{\mathrm{O}}^{+} / \mathrm{V}_{\mathrm{O}}$ ratio (Figure 8). More importantly, these two reactions erase the $\left(\mathrm{V}_{\mathrm{O}}-\mathrm{V}_{\mathrm{O}}^{+}\right)$tunneling pairs, proposed as source of electric noise. As a drawback, an excess of $\mathrm{V}_{\mathrm{O}}^{+}$and $\mathrm{O}_{\mathrm{i}}^{-}$can be also detrimental to the optical coherence lifetime for example by increasing disorder and TLS effect. Therefore, it is observed that $T_{2}$ decreases as the oxygen plasma treatment overcomes a given time duration (Figure 5(b)). The increased amount of interstitials following the oxygen plasma treatment can also explain the observed inhomogeneous linewidth broadening (Figure 5(b)) and induced compressive strain in the lattice (line blueshift). Further optimization of the parameters involved in the plasma creation as the MW power and the oxygen pressure would be required to favor $\mathrm{V}_{\mathrm{O}}$ recombination (first reaction) while limiting $\mathrm{V}_{\mathrm{O}}^{+}$and oxygen excess in the lattice (second reaction).

Another important aspect for QT applications is the ability of our synthesis and posttreatment strategy to yield dispersed single crystalline NPs. This is required to e.g. embed 
particles in small mode volume, high-finesse fiber cavities. Moreover, single crystalline particles maximize, for a given size, the number of ions that can interact with electric and magnetic fields, including light, in the same way. This is important for accurate control of optical and spin quantum states e.g. in scalable processors or memories. ${ }^{18}$ Single crystalline particles are achieved thanks to the two-step high temperature annealing. It cannot be obtained by the MW oxygen plasma treatment alone, which does not change the NPs structure nor morphology (Figures $\mathbf{2}$ and 3). It is however necessary to increase the coherence lifetimes obtained after the two-step annealing. In conclusion, both high-temperature annealing and MW oxygen plasma treatments provide important advantages and have to be combined to obtain optimized RE NPs for QT. More generally, this process, and in particular the high power oxygen plasma treatment, could be applied to other oxide matrices to reduce/tune oxygen vacancies and related defects, which can limit material performance in a broad range of applications in photonics and electronics.

\section{Conclusion}

We have demonstrated a novel strategy combining a two-step high-temperature annealing in air and a microwave-excited oxygen plasma processing in the synthesis and optimization of $\mathrm{Eu}^{3+}: \mathrm{Y}_{2} \mathrm{O}_{3}$ nanoparticles of $100 \mathrm{~nm}$ size. We performed complete structural investigations on such NPs and showed a progression from polycrystalline to single crystalline objects without substantial particle-aggregation under high-temperature annealing up to $1200{ }^{\circ} \mathrm{C}$. More importantly, $T_{2}$ extension up to a factor 5 was successfully achieved by the oxygen plasma treatment. These promising results confirm nanoscale $\mathrm{Eu}^{3+}: \mathrm{Y}_{2} \mathrm{O}_{3} \mathrm{NPs}$ as very appealing candidates for quantum information storage and processing. We conclude that the microwaveexcited oxygen plasma treatment efficiently tunes oxygen-related defects and decreases the electric noise in the NPs. In particular, we propose that it reduces charge tunneling between close-lying oxygen vacancies. Since these non-stoichiometric defects are common in oxides, 
such defect engineering could be potentially applied to other RE oxide materials to fine-tune the local environments and charge variations around the RE ions. Thus, this could enable to achieve desirable, electrical, luminescence and/or optical coherence properties for a wealth of applications.

\section{Methods}

$\mathrm{Eu}^{3+}$ :YOC nanoparticles synthesis. 0.3 at.\% $\mathrm{Eu}^{3+}:$ YOC NPs were synthesized by homogeneous precipitation from aqueous solutions of yttrium nitrate $\mathrm{Y}\left(\mathrm{NO}_{3}\right)_{3} \cdot 6 \mathrm{H}_{2} \mathrm{O}(99.99$ $\%$ pure, Alfa Aesar), europium nitrate $\mathrm{Eu}\left(\mathrm{NO}_{3}\right)_{3} \cdot 6 \mathrm{H}_{2} \mathrm{O}(99.999 \%$ pure, Alfa Aesar) and urea $\mathrm{CO}\left(\mathrm{NH}_{2}\right)_{2}(>99 \%$ pure, Sigma), with metal and urea concentrations of $7.5 \mathrm{mmol}$ $\mathrm{L}^{-1}$ and $3 \mathrm{~mol} \mathrm{~L}{ }^{-1}$ respectively. The mixed solution was heated at $85{ }^{\circ} \mathrm{C}$ for $24 \mathrm{~h}$ in a teflon reactor, leading to the precipitation of $\mathrm{Eu}^{3+}: \mathrm{Y}(\mathrm{OH}) \mathrm{CO}_{3} \cdot n \mathrm{H}_{2} \mathrm{O}\left(\mathrm{Eu}^{3+}: \mathrm{YOC}\right)$ NPs. Once cooled down to room temperature, the NPs were washed once with distilled water and twice with absolute ethanol to remove synthesis byproducts. Every washing was followed by centrifugation at $13000 \mathrm{rpm}$ and $4{ }^{\circ} \mathrm{C}$. Finally, $\mathrm{Eu}^{3+}$ :YOC NPs of $140 \mathrm{~nm}$ average size were collected in the form of white powders after drying at $80^{\circ} \mathrm{C}$ for $24 \mathrm{~h}$.

High-temperature annealing treatment. A two-step annealing process is proposed in this work, which allows for high temperature treatment of small NPs $(<150 \mathrm{~nm})$ without significant particle aggregation. The first annealing is performed at $800{ }^{\circ} \mathrm{C}$ for $18 \mathrm{~h}$, with a heating rate of $5{ }^{\circ} \mathrm{C} \mathrm{min}^{-1}$, to transform the $\mathrm{Eu}^{3+}: \mathrm{YOC}$ precursor into $\mathrm{Eu}^{3+}: \mathrm{Y}_{2} \mathrm{O}_{3}$ phase (JCPDS 01-080-6433). The resulting $\mathrm{Y}_{2} \mathrm{O}_{3} \mathrm{NPs}$ are polycrystalline, with 100-nm-diameter average size. We note that size reduction with respect to the as-synthesized $\mathrm{Eu}^{3+}$ :YOC NPs is expected ${ }^{24}$. Then, a second annealing treatment is applied at $1200{ }^{\circ} \mathrm{C}$ for $6 \mathrm{~h}$, with a heating rate of $3{ }^{\circ} \mathrm{C} \mathrm{min}^{-1}$, to obtain dispersed single crystalline nanoparticles. Treatment duration and temperature are optimized for this aim and also for long $T_{2}$. No $T_{2}$ improve- 
ment is observed for longer treatments, and higher temperatures than $1200^{\circ} \mathrm{C}$ lead to severe particle aggregation. After each treatment, the powders are ground to break the soft aggregates. The cooling rate was set to $5^{\circ} \mathrm{C} \min ^{-1}$ in both cases.

Microwave oxygen plasma processing. A MW oxygen plasma treatment was applied to the $\mathrm{Eu}^{3+}: \mathrm{Y}_{2} \mathrm{O}_{3}$ NPs after the two-step annealing process. For this, the $\mathrm{Eu}^{3+}: \mathrm{Y}_{2} \mathrm{O}_{3}$ powders are spread onto a glass slide and introduced into a home-made plasma chamber. The chamber consists of a MW cavity in which a $2.45 \mathrm{GHz}$ standard microwave source can deliver $900 \mathrm{~W}$. A vacuum sealed quartz bell jar was pumped down to $10^{-2}$ mbar before being flushed with a $10 \mathrm{sccm}$ pure $\mathrm{O}_{2}$ flow for a few minutes. The pressure was then set to $0.5-1$ mbar by regulating the pumping speed with a butterfly valve (Figure 12). As soon as the microwave excitation was switched on, the $\mathrm{O}_{2}$ plasma lit up in the low pressure region of the bell jar. For the standard optimized treatment, the plasma was sustained for 3 minutes, then the system was left to cool down for a few minutes before the plasma was switched on once again for another 3 minutes. The chamber was eventually vented to atmospheric pressure and the treated nanoparticles collected for further structural and spectroscopic characterizations.

To investigate the influence of the oxygen plasma on the NPs properties, several atmospheres and plasma duration times were tested. In particular, pure Ar gases and $50 \%$ Ar: $50 \% \mathrm{O}_{2}$ mixed gases were tested under the same plasma conditions and the plasma duration time was varied from 1-5 minutes. These optimization studies were done with two different batches of $0.3 \%$ at. $\mathrm{Eu}^{3+}: \mathrm{Y}_{2} \mathrm{O}_{3}$ NPs: one with $394 \pm 40 \mathrm{~nm}$ average size, and one with 140 $\pm 45 \mathrm{~nm}$ average size. These two batches were also produced following the route described above, with the exception of a lower urea content $\left(0.3 \mathrm{~mol} \mathrm{~L}{ }^{-1}\right)$ for the first batch, yielding larger size particles ${ }^{24}$, and a single annealing treatment at $1200{ }^{\circ} \mathrm{C}$ for $6 \mathrm{~h}$ in both cases. All other studies presented in the manuscript were carried out in the same batch of NPs (100 nm size), produced with the fully optimized procedure, i.e. annealed two times, and treated under $\mathrm{O}_{2}$ plasma for 2 times 3 minutes. 
Structural characterizations. Morphology, size and dispersion of the NPs were observed by scanning electron microscopy (SEM, Zeiss Leo1530) and transmission electron microscopy (TEM, JEOL-JEM-100CX I operating at 100 kV). Particle size and distribution were calculated by Image J software based on at least 100 nanoparticles from different TEM images, assuming that all NPs had spherical shapes. X-ray diffraction (XRD) measurements were performed on a Panalytical XPert Pro diffractometer using monochromatic CuK $\alpha 1$ radiation $(\lambda=154.060 \mathrm{pm})$, in the $2 \theta$ range between $12^{\circ}$ and $150^{\circ}$, with a step size of $0.0065^{\circ}$. Crystalline domain sizes were deduced from diffraction peaks at $20.51^{\circ}, 29.16^{\circ}, 48.54^{\circ}$ and $71.06^{\circ}$ by Scherrer equation:

$$
D=\frac{K \lambda}{\beta \cos (\theta)}
$$

where $D$ is the crystalline domain size, $\beta$ is the peak broadening at FWHM corrected by the instrumental response, $\lambda$ is the $\mathrm{Cu}_{K \alpha}$ radiation wavelength, $K$ is the shape factor, here set to 0.89 , and $\theta$ the Bragg diffraction angle.

Low-temperature high-resolution and coherent spectroscopy. High-resolution and coherent spectroscopy investigations at low temperature were carried out on $\mathrm{Eu}^{3+}$ ions located at the $\mathrm{Y}^{3+} \mathrm{C}_{2}$ symmetry site of $\mathrm{Y}_{2} \mathrm{O}_{3}$. The powders were placed in a brass holder between two glass plates forming a layer with a thickness of $500 \mu \mathrm{m}$. Cryogenic conditions were provided by a He bath cryostat (Janis SVT-200), operated in liquid and gas modes. The sample temperature was controlled with a Si diode (Lakeshore DT-670) attached to the sample holder. Inhomogenenous linewidths for the ${ }^{7} \mathrm{~F}_{0} \rightarrow{ }^{5} \mathrm{D}_{0}$ transition of $\mathrm{Eu}^{3+}$ ions were recorded at $12 \mathrm{~K}$ by monitoring the ${ }^{5} \mathrm{D}_{0} \rightarrow{ }^{7} \mathrm{~F}_{2}$ fluorescence while scanning a $\mathrm{CW}$ frequencystabilized ring dye laser (Sirah Matisse DS, $300 \mathrm{kHz}$ linewidth) pumped by a Coherent Verdi G10 laser. A long-pass filter (590 nm cut-off wavelength) was placed in front of the detector (APD Thorlabs $110 \mathrm{~A} / \mathrm{M}$ ) to reject the excitation light. Optical $T_{2}$ values were obtained at $1.4 \mathrm{~K}$ by two-pulse photon echo spectroscopy with heterodyne detection ${ }^{16,17,19}$. 
For this, pulsed sequences were created by modulating the CW laser output with an acoustooptic modulator (AA Opto Electronic MT200-A0.5,VIS) driven by an arbitrary waveform generator (Agilent N8242A). Scattered light transmitted through the powders was collected and then focussed by a series of large-diameter lenses on the APD detector (Figure 4(a)). The length of the exciting and rephasing pulses in the sequence was set to 1 and $1.5 \mu \mathrm{s}$ respectively and their power to $\sim 300 \mathrm{~mW}$ (Figure 13). The decay of the photon echo amplitude follows:

$$
A_{\text {echo }}=A_{0} e^{\frac{-2 \tau}{T_{2}}}
$$

where $\tau=0$ is the time delay between the first and second pulse in the sequence, and $A_{0}$ is the echo amplitude at $\tau=0 . T_{2}$ values were derived from experimental echo decay data by single exponential fit. Homogeneous linewidths $\left(\Gamma_{\mathrm{h}}\right)$ were then determined as $\Gamma_{\mathrm{h}}=\left(\pi T_{2}\right)^{-1}$.

Optical spectroscopy and defect characterizations. FT-IR studies were performed in transmission mode between 400 and $4000 \mathrm{~cm}^{-1}$ with a Bruker Tensor 27 spectrometer. Samples were prepared for measurements using the conventional KBr pellet method. Photoluminescence (PL) spectra were obtained at room temperature under $390 \mathrm{~nm}$ excitation by a tunable optical parametric oscillator (OPO) pumped by a $\mathrm{Nd}^{3+}$ YAG Q-switched laser (Ekspla NT342B-SH with 6 ns pulse length and $10 \mathrm{~Hz}$ repetition rate). The spectra were recorded by a spectrometer (Acton SP2300) equipped with 300 grooves/mm holographic grating and an ICCD camera (Princeton Instruments). A time-gated detection was carried out to separate emissions from $\mathrm{Eu}^{3+}$ ions $(500 \mu$ s gate width starting after $50 \mu \mathrm{s})$ and from defect centers (500 ns gate width starting at $50 \mathrm{~ns}$ ). Decay measurements were recorded using the same setup except for a photomultiplier tube detector. Decay curves for the ${ }^{5} \mathrm{D}_{0}$, ${ }^{5} \mathrm{D}_{1}$ and ${ }^{5} \mathrm{D}_{2}$ energy levels of $\mathrm{Eu}^{3+}$ ions were recorded at 611,535 and $516 \mathrm{~nm}$ respectively with an excitation wavelength of $465 \mathrm{~nm}$. Decay data were recorded with a digital oscilloscope. Cathodoluminescence (CL) measurements were performed by a SEM (Zeiss EVO MA15) equipped with a Horiba HCLUE CL system. The electron gun was operated with an 
accelerating voltage of $10 \mathrm{kV}$ and a probe current of $10 \mathrm{nA}$. Light emitted in the UV-visible range by the NPs was collected by a motorized and retractable curved mirror and sent to a spectrometer HORIBA TRIAX 500 equipped with a 600 grooves/mm grating and a slit size of $100 \mu \mathrm{m}$ to disperse the light onto a Pelletier cooled CCD camera. Electron paramagnetic resonance (EPR) measurements were performed using a Bruker Elexsys E500 spectrometer and a Super-high-sensitivity probehead in X-band ( $\sim 9.5 \mathrm{GHz})$. EPR spectra were recorded with a microwave power of $10 \mathrm{~mW}$.

\section{Acknowledgement}

Shuping Liu and Alexandre Fossati contributed equally. This project has received funding from the European Union Horizon 2020 Research and Innovation Programme under grant

agreement no. 712721 (NanOQTech). S. Liu is supported by the Key R\&D Program of Guangdong province (Grant No. 2018B030325001). We thank Patricia Beaunier for her help with TEM measurements and Nadia Touati for assistance during EPR experiments.

\section{Supporting Information Available}

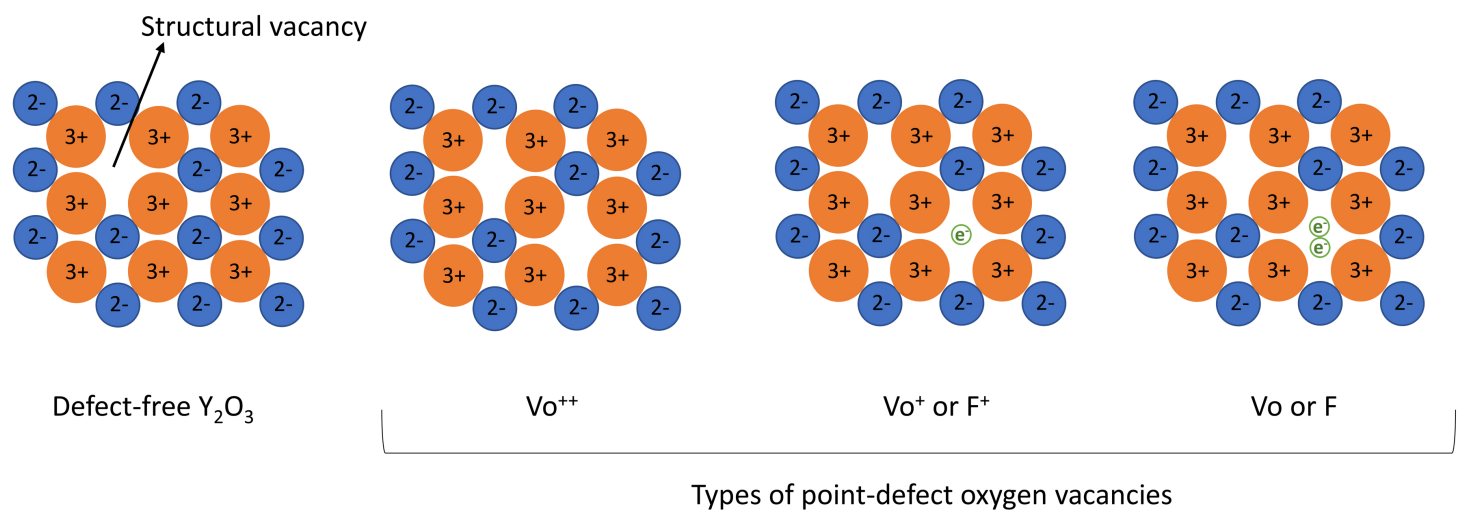

Figure 9: Schematic representation of the types of oxygen vacancies in $\mathrm{Y}_{2} \mathrm{O}_{3}$.

This material is available free of charge via the Internet at http://pubs.acs.org/. 


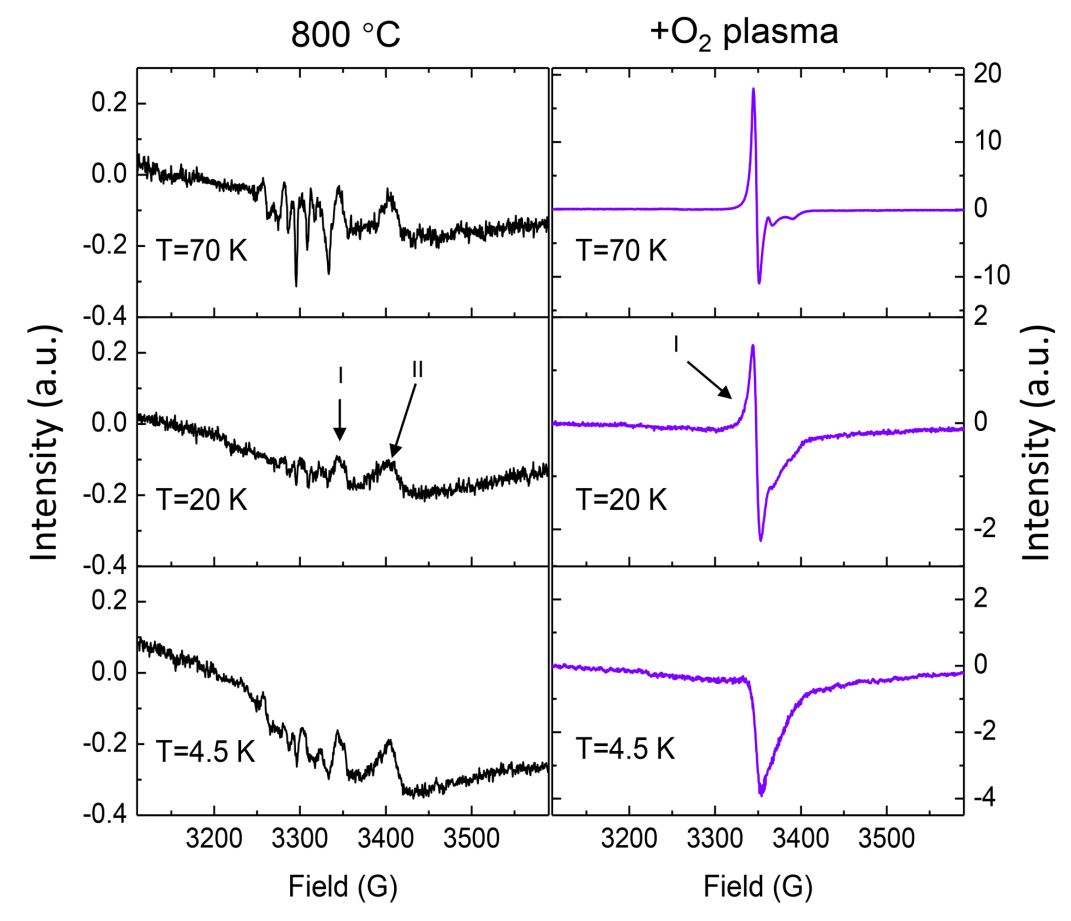

Figure 10: EPR spectra taken at various temperatures before and after $\mathrm{O}_{2}$ plasma treatment. The $\mathrm{MW} \mathrm{O}_{2}$ plasma treatment was here applied immediately after the $800{ }^{\circ} \mathrm{C}$ annealing, skipping the $1200{ }^{\circ} \mathrm{C}$ step. These measurements were done on a different batch of $\mathrm{Eu}^{3+}: \mathrm{Y}_{2} \mathrm{O}_{3} \mathrm{NPs}$, with $60 \mathrm{~nm}$ average size, obtained by a modified homogeneous precipitation route.

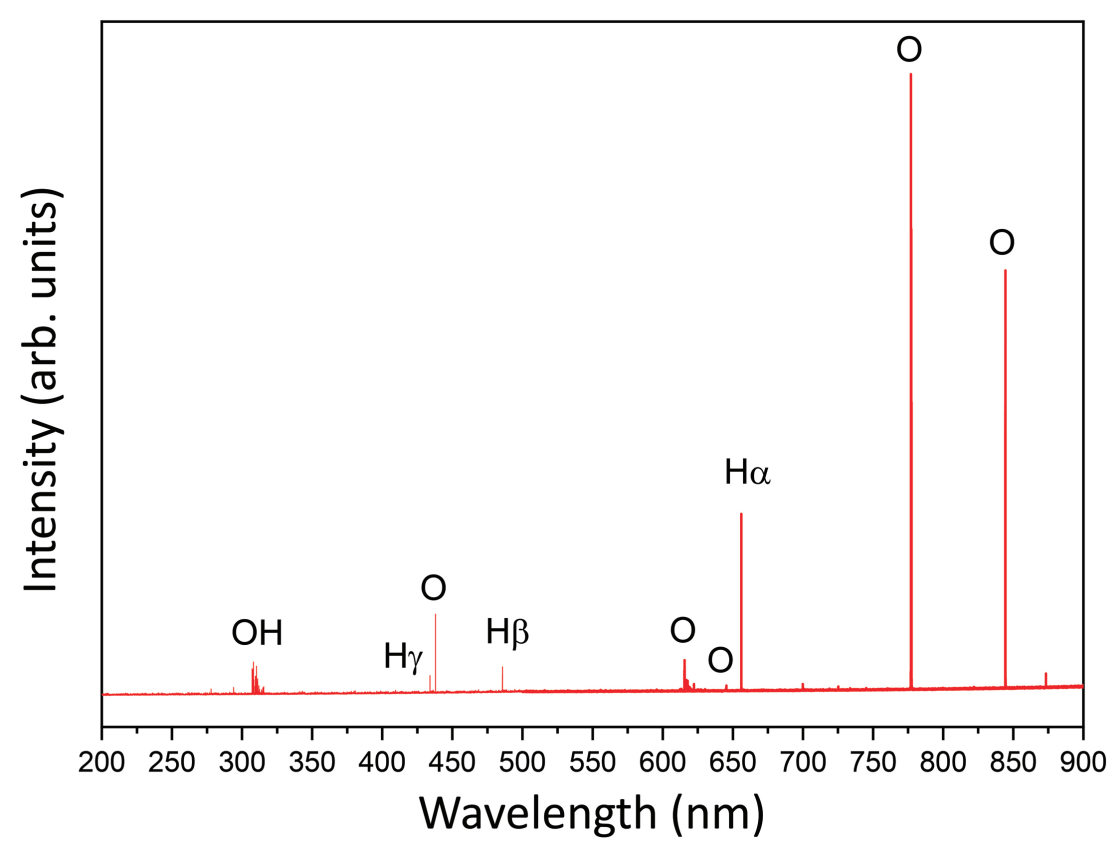

Figure 11: Optical emission spectrum of a pure $\mathrm{O}_{2}$ plasma used to treat $\mathrm{Eu}^{3+}: \mathrm{Y}_{2} \mathrm{O}_{3}$ NPs. The main lines are identified as corresponding to $\mathrm{O}, \mathrm{H}$ and $\mathrm{OH}$ species. 

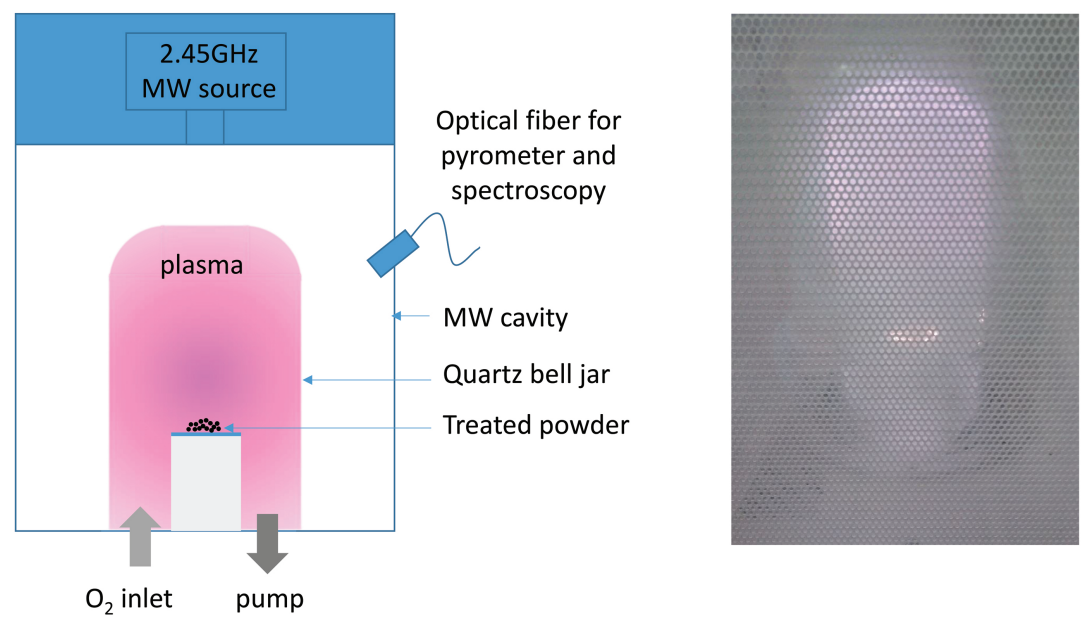

Figure 12: Schematics of the MW plasma apparatus and picture of the chamber during $\mathrm{O}_{2}$ plasma generation.

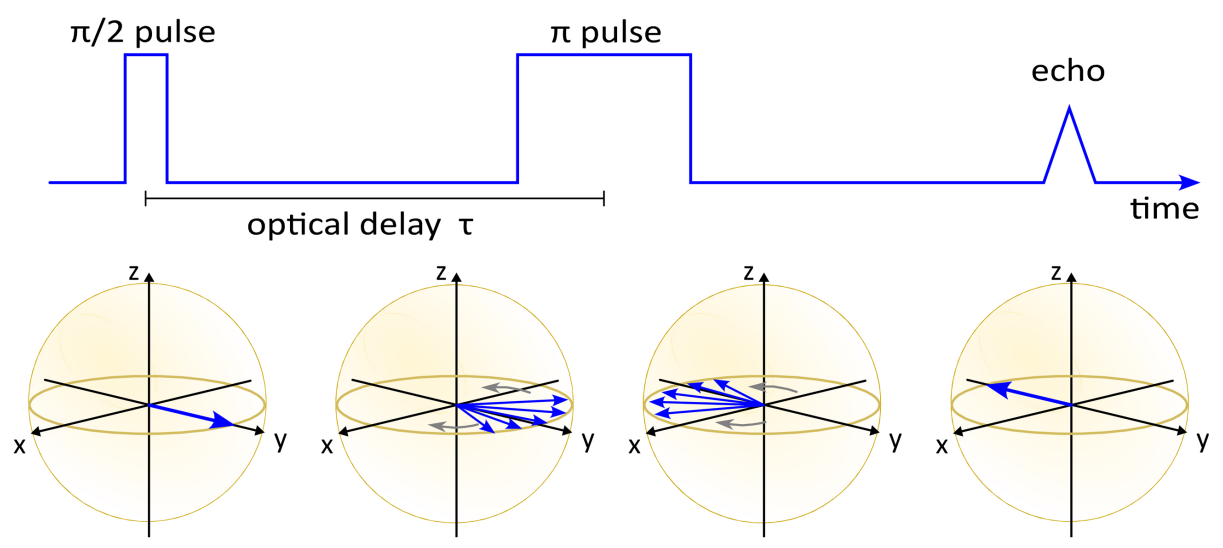

Figure 13: Two-pulse photon echo sequence (upper) and optical coherence phase evolution represented at the Bloch sphere (lower). The optical coherence lifetime is evaluated by monitoring the decay of the photon echo amplitude when increasing the time delay $\tau$ between the excitation pulse $(\pi / 2)$ and the rephasing pulse $(\pi)$. 


\section{References}

1. Acín, A.; Bloch, I.; Buhrman, H.; Calarco, T.; Eichler, C.; Eisert, J.; Esteve, D.; Gisin, N.; Glaser, S. J.; Jelezko, F. et al. The quantum technologies roadmap: a European community view. New J. Phys. 2018, 20, 080201.

2. Goldner, P.; Ferrier, A.; Guillot-Noël, O. In Handbook on the Physics and Chemistry of Rare Earths; Bünzli, J.-C. G., Pecharsky, V. K., Eds.; Elsevier: Amsterdam, 2015; pp $1-78$.

3. Achard, J.; Jacques, V.; Tallaire, A. CVD diamond single crystals with NV centres: a review of material synthesis and technology for quantum sensing applications. J. Phys. D: Appl. Phys. 2020, 1-43.

4. Atatüre, M.; Englund, D.; Vamivakas, N.; Lee, S.-Y.; Wrachtrup, J. Material platforms for spin-based photonic quantum technologies. Nat. Rev. Mater. 2018, 3, 1-14.

5. Equall, R. W.; Cone, R. L.; Macfarlane, R. M. Homogeneous broadening and hyperfine structure of optical transitions in $\mathrm{Pr}^{3+}: \mathrm{Y}_{2} \mathrm{SiO}_{5}$. Physical Review B 1995, 52, 3963-3969.

6. Arcangeli, A.; Lovrić, M.; Tumino, B.; Ferrier, A.; Goldner, P. Spectroscopy and coherence lifetime extension of hyperfine transitions in ${ }^{151} \mathrm{Eu}^{3+}: \mathrm{Y}_{2} \mathrm{SiO}_{5}$. Phys. Rev. B 2014, $\underline{89}, 184305$.

7. Zhong, M.; Hedges, M. P.; Ahlefeldt, R. L.; Bartholomew, J. G.; Beavan, S. E.; Wittig, S. M.; Longdell, J. J.; Sellars, M. J. Optically addressable nuclear spins in a solid with a six-hour coherence time. Nature 2015, 517, 177.

8. Businger, M.; Tiranov, A.; Kaczmarek, K. T.; Welinski, S.; Zhang, Z.; Ferrier, A.; Goldner, P.; Afzelius, M. Optical Spin-Wave Storage in a Solid-State Hybridized ElectronNuclear Spin Ensemble. Phys. Rev. Lett. 2020, 124, 053606. 
9. Puigibert, M. 1. G.; Askarani, M. F.; Davidson, J. H.; Verma, V. B.; Shaw, M. D.; Nam, S. W.; Lutz, T.; Amaral, G. C.; Oblak, D.; Tittel, W. Entanglement and nonlocality between disparate solid-state quantum memories mediated by photons. Phys. Rev.

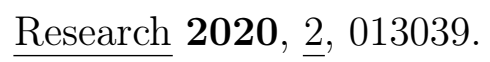

10. Bussières, F.; Clausen, C.; Tiranov, A.; Korzh, B.; Verma, V. B.; Nam, S. W.; Marsili, F.; Ferrier, A.; Goldner, P.; Herrmann, H. et al. Quantum teleportation from a telecomwavelength photon to a solid-state quantum memory. Nature Photonics 2014, $\underline{8}, 775$.

11. Zhong, T.; Kindem, J. M.; Bartholomew, J. G.; Rochman, J.; Craiciu, I.; Miyazono, E.; Bettinelli, M.; Cavalli, E.; Verma, V.; Nam, S. W. et al. Nanophotonic rare-earth quantum memory with optically controlled retrieval. Science $\mathbf{2 0 1 7}$,

12. Dibos, A. M.; Raha, M.; Phenicie, C. M.; Thompson, J. D. Atomic Source of Single Photons in the Telecom Band. Phys. Rev. Lett. 2018, 120, 243601.

13. Bernardo, C.; Julia, B.; Thomas, H.; Franziska, O.; Karmel de Oliveira, L.; Theodor, W. H.; Alban, F.; Philippe, G.; Hugues de, R.; David, H. Cavity-enhanced spectroscopy of a few-ion ensemble in $\mathrm{Eu}^{3+}: \mathrm{Y}_{2} \mathrm{O}_{3}$. New Journal of Physics 2018, $\underline{20}$, 095006.

14. Zhong, T.; Goldner, P. Emerging rare-earth doped material platforms for quantum nanophotonics. Nanophotonics 2019, 8, 2003-2015.

15. Schmitt, S.; Gefen, T.; Stürner, F. M.; Unden, T.; Wolff, G.; Müller, C.; Scheuer, J.; Naydenov, B.; Markham, M.; Pezzagna, S. et al. Submillihertz magnetic spectroscopy performed with a nanoscale quantum sensor. Science 2017, 356, 832-837.

16. Bartholomew, J. G.; Lima, K. D.; Ferrier, A.; Goldner, P. Optical Line Width Broadening Mechanisms at the $10 \mathrm{kHz}$ Level in $\mathrm{Eu}^{3+}: \mathrm{Y}_{2} \mathrm{O}_{3}$ Nanoparticles. Nano Lett 2017, 17, 778787. 
17. Liu, S.; Serrano, D.; Fossati, A.; Tallaire, A.; Ferrier, A.; Goldner, P. Controlled size reduction of rare earth doped nanoparticles for optical quantum technologies. RSC Advances 2018, $\underline{8}, 37098-37104$.

18. Serrano, D.; Karlsson, J.; Fossati, A.; Ferrier, A.; Goldner, P. All-optical control of longlived nuclear spins in rare-earth doped nanoparticles. Nature Communications 2018, $\underline{9}$, 2127.

19. Serrano, D.; Deshmukh, C.; Liu, S.; Tallaire, A.; Ferrier, A.; de Riedmatten, H.; Goldner, P. Coherent optical and spin spectroscopy of nanoscale $\operatorname{Pr}^{3+}: \mathrm{Y}_{2} \mathrm{O}_{3}$. Physical Review B 2019, 100, 144304.

20. Macfarlane, R. M.; Shelby, R. M. Sub-kilohertz optical linewidths of the 7F0 $\leftrightarrow$ 5D0 transition in Y2O3:Eu3+. Opt. Commun. 1981, 39, 169-171.

21. Kunkel, N.; Bartholomew, J.; Binet, L.; Ikesue, A.; Goldner, P. High-Resolution Optical Line Width Measurements as a Material Characterization Tool. Journal of Physical Chemistry C 2016, 120, 13725-13731.

22. Karlsson, J.; Kunkel, N.; Ikesue, A.; Ferrier, A.; Goldner, P. Nuclear spin coherence properties of 151Eu3 + and 153Eu3 + in a Y2O3 transparent ceramic. J. Phys.: Condens. Matter 2017, 29, 125501.

23. Korner, N.; Beck, E.; Dommann, A.; Onda, N.; Ramm, J. Hydrogen plasma chemical cleaning of metallic substrates and silicon wafers. Surface and Coatings Technology 1995, 76-77, $731-737$.

24. de Oliveira Lima, K.; Rocha Gonçcalves, R.; Giaume, D.; Ferrier, A.; Goldner, P. Influence of defects on sub-Åoptical linewidths in $\mathrm{Eu}^{3+}: \mathrm{Y}_{2} \mathrm{O}_{3}$ particles. Journal of Luminescence 2015, 168, 276-282. 
25. Macfarlane, R. M. High-resolution laser spectroscopy of rare-earth doped insulators: a personal perspective. Journal of Luminescence 100, 1-20.

26. Stoneham, A. M. The theory of the strain broadened line shapes of spin resonance and optical zero phonon lines. Proceedings of the Physical Society 1966, 89, 909.

27. Welinski, S.; Thiel, C. W.; Dajczgewand, J.; Ferrier, A.; Cone, R. L.; Macfarlane, R. M.; Chaneliere, T.; Louchet-Chauvet, A.; Goldner, P. Effects of disorder on optical and electron spin linewidths in Er3+,Sc3+:Y2SiO5. Optical Materials 63, 69-75.

28. Flinn, G. P.; Jang, K. W.; Ganem, J.; Jones, M. L.; Meltzer, R. S.; Macfarlane, R. M. Sample-dependent optical dephasing in bulk crystalline samples of $\mathrm{Y}^{2} \mathrm{O}^{3}: \mathrm{Eu}^{3+}$. Physical

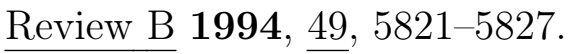

29. Perrot, A.; Goldner, P.; Giaume, D.; Lovric, M.; Andriamiadamanana, C.; Goncalves, R. R.; Ferrier, A. Narrow optical homogeneous linewidths in rare earth doped nanocrystals. Physical Review Letters 2013, 111, 203601.

30. Tareen, J.; Kutty, T. N.; Krishnamurty, K. Hydrothermal growth of $\mathrm{Y}_{2}\left(\mathrm{CO}_{3}\right)_{3} \mathrm{n} \mathrm{H}_{2} \mathrm{O}$ (tengerite) single crystals. Journal of Crystal Growth 1980, 49, $761-765$.

31. Krishna, R. H.; Nagabhushana, B. M.; Nagabhushana, H.; Murthy, N. S.; Sharma, S. C.; Shivakumara, C.; Chakradhar, R. P. S. Effect of Calcination Temperature on Structural, Photoluminescence, and Thermoluminescence Properties of $\mathrm{Y}_{2} \mathrm{O}_{3}: \mathrm{Eu}^{3+}$ Nanophosphor. The Journal of Physical Chemistry C 2013, 117, 1915-1924.

32. Som, S.; Sharma, S. K. Eu ${ }^{3+} / \mathrm{Tb}^{3+}$-codoped $\mathrm{Y}_{2} \mathrm{O}_{3}$ nanophosphors: Rietveld refinement, bandgap and photoluminescence optimization. Journal of Physics D: Applied Physics 2012, $\underline{45}, 415102$.

33. Kumar, Y.; Pal, M.; Herrera, M.; Mathew, X. Effect of Eu ion incorporation on the 
emission behavior of $\mathrm{Y}_{2} \mathrm{O}_{3}$ nanophosphors: A detailed study of structural and optical properties. Optical Materials 2016, 60, 159-168.

34. Scarafagio, M.; Tallaire, A.; Tielrooij, K.-J.; Cano, D.; Grishin, A.; Chavanne, M.-H.; Koppens, F. H. L.; Armelle, R.; Cassir, M.; Serrano, D. et al. Ultrathin Eu- and ErDoped $\mathrm{Y}_{2} \mathrm{O}_{3}$ Films with Optimized Optical Properties for Quantum Technologies. The Journal of Physical Chemistry C 2019, 123, 13354-13364.

35. Zheng, J. X.; Ceder, G.; Maxisch, T.; Chim, W. K.; Choi, W. K. Native point defects in yttria and relevance to its use as a high-dielectric-constant gate oxide material: Firstprinciples study. Physical Review B 2006, $\underline{73}, 104101$.

36. Jollet, F.; Noguera, C.; Gautier, M.; Thromat, N.; Duraud, J.-P. Influence of Oxygen Vacancies on the Electronic Structure of Yttrium Oxide. Journal of the American Ceramic Society 1991, 74, 358-364.

37. Bordun, O. M. Influence of Oxygen Vacancies on the Luminescence Spectra of $\mathrm{Y}_{2} \mathrm{O}_{3}$ Thin Films. Journal of Applied Spectroscopy 2002, 69, 430-433.

38. Zorenko, Y.; Zorenko, T.; Voznyak, T.; Mandowski, A.; Xia, Q.; Batentschuk, M.; Friedrich, J. Luminescence of $\mathrm{F}+$ and $\mathrm{F}$ centers in $\mathrm{AI}_{2} \mathrm{O}_{3}-\mathrm{Y}_{2} \mathrm{O}_{3}$ oxide compounds. IOP Conference Series: Materials Science and Engineering 2010, 15, 012060.

39. Singh, V.; Rai, V. K.; Ledoux-Rak, I.; Watanabe, S.; Gundu Rao, T. K.; Chubaci, J. F. D.; Badie, L.; Pelle, F.; Ivanova, S. NIR to visible up-conversion, infrared luminescence, thermoluminescence and defect centres in $\mathrm{Y}_{2} \mathrm{O}_{3}$ : Er phosphor. Journal of Physics D: Applied Physics 2009, $\underline{42,065104 .}$

40. Santos, S. C.; Rodrigues, O.; Campos, L. L. EPR response of yttria micro rods activated by europium. 2018, 764, 136-141. 
41. Costantini, J.-M.; Beuneu, F.; Gourier, D.; Trautmann, C.; Calas, G.; Toulemonde, M. Colour centre production in yttria-stabilized zirconia by swift charged particle irradiations. Journal of Physics: Condensed Matter 2004, 16, 3957-3971.

42. Lacroix, B.; Paumier, F.; Gaboriaud, R. J. Crystal defects and related stress in $\mathrm{Y}_{2} \mathrm{O}_{3}$ thin films: Origin, modeling, and consequence on the stability of the C-type structure. $\underline{\text { Physical Review B 2011, 84, } 014104 .}$

43. Sarkar, A.; Khan, G. G. The formation and detection techniques of oxygen vacancies in titanium oxide-based nanostructures. Nanoscale 2019, 11, 3414-3444.

44. Cockayne, E. Influence of oxygen vacancies on the dielectric properties of hafnia: Firstprinciples calculations. Phys. Rev. B 2007, 75, 094103.

45. Kevane, C. J. Oxygen Vacancies and Electrical Conduction in Metal Oxides. Phys. Rev. 1964, 133, A1431-A1436.

46. Bluvstein, D.; Zhang, Z.; McLellan, C. A.; Williams, N. R.; Jayich, A. C. B. Extending the Quantum Coherence of a Near-Surface Qubit by Coherently Driving the Paramagnetic Surface Environment. Phys. Rev. Lett. 2019, 123, 146804. 


\section{Graphical TOC Entry}

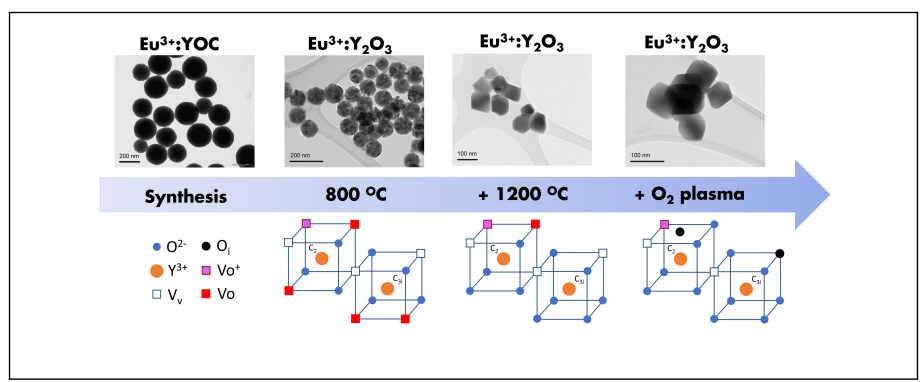

